
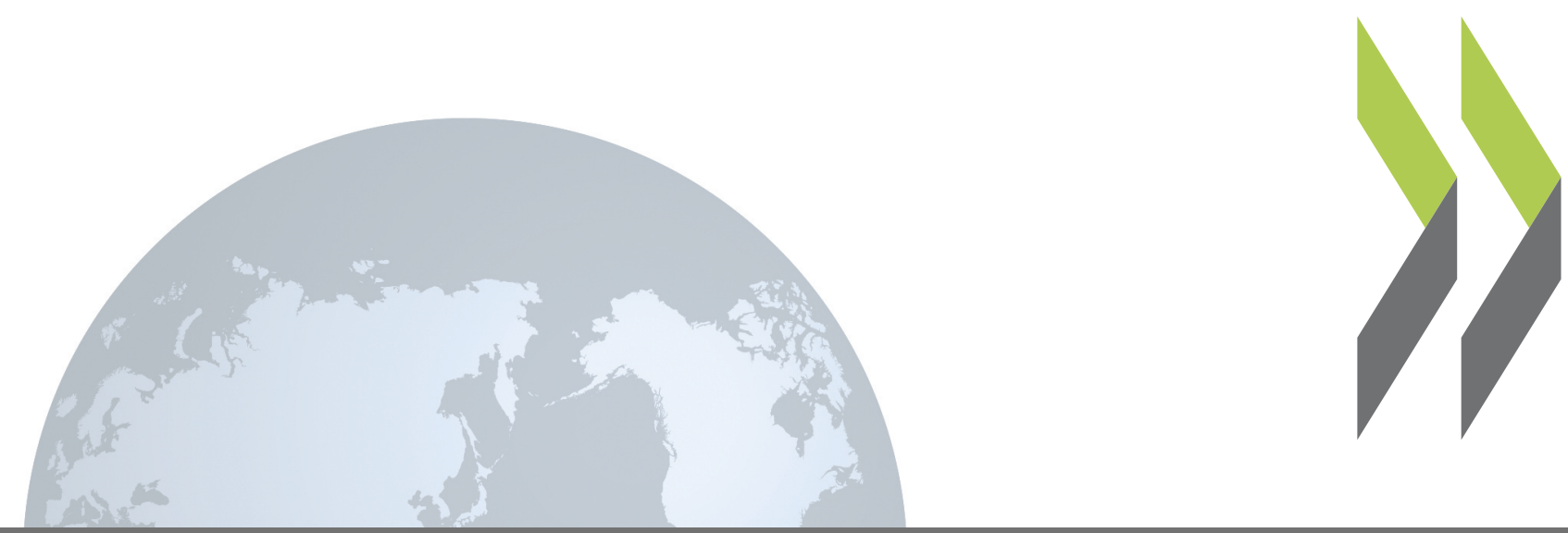

Documents SIGMA No. 45

La passation des marchés publics dans les Etats membres de l'UE :

Réglementation applicable aux marchés dont le montant est inférieur aux seuils européens et relatifs à des secteurs non couverts par les règles détaillées des directives européennes

\title{
OCDE
}


SIGMA

Soutien à l'amélioration des institutions publiques et des systèmes de gestion Initiative conjointe de l'OCDE et de l'UE, financée principalement par l'UE

\section{LA PASSATION DES MARCHÉS PUBLICS \\ DANS LES ÉTATS MEMBRES DE L'UE :}

RÉGLEMENTATION APPLICABLE AUX MARCHÉS DONT LE MONTANT EST

INFÉRIEUR AUX SEUILS EUROPÉENS ET

RELATIFS À DES SECTEURS NON COUVERTS PAR LES RÈGLES DÉTAILLÉES DES

DIRECTIVES EUROPÉENNES

\section{DOCUMENT SIGMA N ${ }^{\circ} 45$}

\section{MAI 2010}




\section{LE PROGRAMME SIGMA}

Le Programme Sigma - Soutien à l'amélioration des institutions publiques et des systèmes de gestion - est une initiative conjointe de l'Organisation de coopération et de développement économiques (OCDE) et de l'Union européenne, financée principalement par l'UE.

En œuvrant en partenariat avec les pays bénéficiaires, Sigma contribue à l'amélioration des institutions publiques et des systèmes de gestion :

En évaluant les progrès de la réforme et en définissant des priorités par rapport aux références que constituent les bonnes pratiques européennes et la législation existante au sein de l'UE (l'acquis communautaire)

En soutenant la consolidation des institutions ainsi que la mise en place de cadres et de procédures légales conformes aux normes et aux bonnes pratiques européennes

- $\quad$ En aidant les donateurs intra et extra-européens à concevoir des projets, à instaurer les conditions préalables à leur réalisation, et en les assistant dans leur mise en œuvre.

Depuis 2008, Sigma soutient les partenaires suivants dans leurs efforts de réforme administrative :

- Pays candidats à l'UE - Croatie, ancienne République yougoslave de Macédoine et Turquie

- Candidats potentiels à l'UE dans les Balkans occidentaux - Albanie, Bosnie-Herzégovine, Monténégro, Serbie et Kosovo (selon le statut défini par la résolution 1244/99 du Conseil de sécurité des Nations Unies) ${ }^{1}$

- Voisins et partenaires européens (ENPI - Instrument européen de voisinage et de partenariat) - Algérie, Arménie, Azerbaïdjan, Biélorussie, Égypte, Géorgie, Israël, Jordanie, Liban, Libye, Moldavie, Maroc, territoires palestiniens occupés, Syrie, Tunisie, Ukraine et Russie ${ }^{2}$.

Le programme Sigma soutient les initiatives de réforme des pays partenaires dans les domaines suivants :

- $\quad$ Structures juridiques, fonction publique et justice : structures juridiques et justice ; fonction publique et structure administrative ; intégrité publique

- Gestion des ressources financières : audit externe ; gestion des dépenses publiques ; contrôle financier interne de l'état ; marchés publics

- Systèmes d'élaboration des politiques et des réglementations : élaboration et coordination des politiques ; politique de réglementation - meilleure réglementation ; élaboration et application de la réforme

Pour plus d'informations sur le programme Sigma, consultez notre site Internet :

http://www.sigmaweb.org

\section{(C) OCDE 2010}

Ceci est une traduction à partir du titre original : Public Procurement in EU Member States: The Regulation of Contract Below the EU Thresholds and in Areas not Covered by the Detailed Rules of the EU Directives [GOV/SIGMA(2010)1/REV1].

Toute demande d'autorisation de reproduction ou de traduction de cette publication à usage commercial ou non-commercial devra être envoyée à rights@oecd.org.

1 Conformément à la résolution 1244 du Conseil de sécurité des Nations Unies, depuis juin 1999, le Kosovo est gouverné par la mission d'administration intérimaire des Nations Unies au Kosovo (MINUK).

2 Comme convenu avec l'Union européenne, les initiatives du Programme Sigma opèrent dans l'immédiat dans neuf pays prioritaires : l'Égypte, la Jordanie, le Maroc et la Tunisie (ENPI-Sud) ; l'Arménie, l'Azerbaïdjan, la Géorgie, la Moldavie et l'Ukraine (ENPI-Est). 


\section{AVANT-PROPOS}

Le nombre de marchés publics inférieurs aux seuils fixés par l'Union européenne ne cesse d'augmenter au point de représenter une part considérable de l'ensemble des marchés publics passés dans tous les États membres de l'UE. Il est de ce fait primordial d'encadrer et d'organiser l'adjudication de ces marchés de manière saine et efficace, en élaborant des politiques et des règles dédiées au niveau national.

Les directives européennes 2004/17 et 18 fournissent un ensemble de procédures visant à coordonner la passation des marchés publics dont le montant excède les seuils de l'UE. Or, cet ensemble de procédures de coordination, que les États membres doivent transposer dans leur droit national, ne couvre pas tous les aspects du processus de passation des marchés publics. Dans le cadre de «l'acquis », il appartient à chacun des États membres d'organiser son propre système d'adjudication, au niveau juridique comme institutionnel, afin d'assurer l'utilisation la plus efficace et la plus rentable possible des ressources publiques.

Sur la base des travaux entrepris avec les nouveaux États membres ainsi qu'avec les pays candidats et les candidats potentiels, Sigma a constaté que les pays sont généralement hésitants quant à la définition du cadre réglementaire à adopter en matière d'adjudication des marchés qui ne relèvent pas du champ d'application des Directives, au risque d'instaurer des procédures et des pratiques inefficaces. Malheureusement, il n'existe aucun examen systématique sur la façon dont les États membres de l'UE élaborent leurs cadres juridiques en dehors du champ d'application des Directives européennes. Une comparaison d'ordre général, comprenant une présentation des modèles et des instruments réglementaires nationaux mis en place dans les États membres de l'UE, se révélera donc d'une grande utilité pour les pays ayant adhéré au programme Sigma.

La présente étude couvre les procédures et autres règles d'adjudication pour les marchés dont les montants sont inférieurs aux seuils fixés par l'UE, et offre également une analyse des politiques ainsi que des pratiques applicables à l'ensemble des marchés dont les montants excèdent les seuils fixés par l'UE, d'égale importance, dans l'optique d'établir un cadre procédural complet au niveau national. Figurent notamment au nombre des domaines qui ne sont pas spécifiquement couverts par les Directives (qui définissent les principes fondamentaux et les obligations applicables) l'organisation des procédures de passation des marchés publics, la préparation et le contenu des dossiers d'appel d'offres, les durées de validité des appels d'offres, la soumission et l'ouverture des offres, les garanties d'adjudication et d'exécution, les modalités clarifiant avec détail les offres, ainsi que la suspension et l'annulation des offres. Revêtiront un intérêt tout particulier les instruments réglementaires, les seuils nationaux, les méthodes de passation des marchés publics, les règles de publication, les règles de participation, les critères de sélection et d'attribution, le cahier des charges ainsi que les recours disponibles s'agissant des marchés inférieurs aux seuils fixés l'UE.

Une meilleure compréhension et une connaissance plus approfondie des procédures et autres pratiques existantes entre les États membres de l'UE devraient inciter les pays partenaires de l'initiative Sigma à élaborer des cadres juridiques efficaces et mieux adaptés à la passation des marchés qui ne sont pas couverts par les Directives européennes. La présente étude fournit des informations sur la situation des États membres sans essayer de tirer de conclusions appréciables ou d'établir des recommandations sur la base de modèles procéduraux privilégiés. 
Sigma tient à remercier ses interlocuteurs dans les États membres pour leur aimable soutien et leur précieuse contribution dans la réalisation de cette étude. Sigma reste convaincu de l'avantage particulièrement utile qu'ont ses pays partenaires à partager leurs informations et leurs connaissances. L'aperçu général fourni par cette étude sur la passation des marchés publics peut également intéresser les États membres eux-mêmes, et dans une plus large mesure, la communauté internationale. 


\section{TABLE DES MATIÈRES}

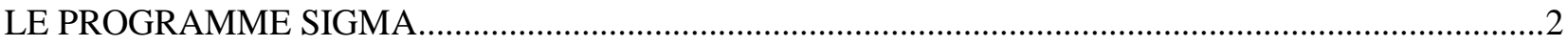

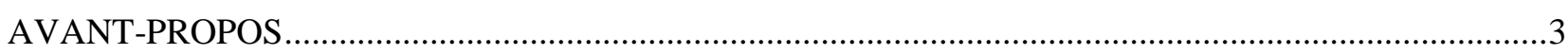

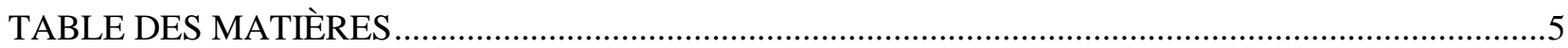

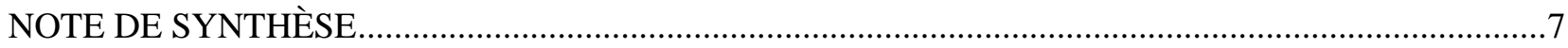

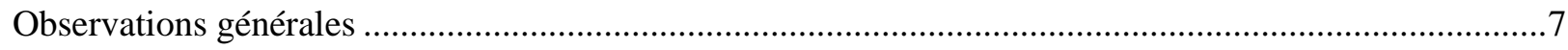

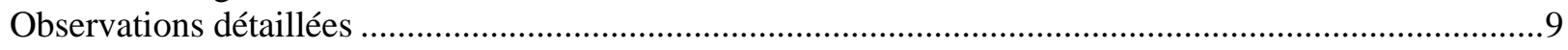

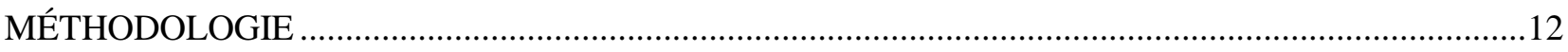

PARTIE I. RÈGLES ET AUTRES PROCÉDURES D'INTÉRÊT PARTICULIER POUR LA PASSATION DE MARCHÉS DONT LA VALEUR EST INFÉRIEURE AUX SEUILS FIXÉS PAR L'UE13

Introduction

1.1 Instrument(s) réglementaire(s) ou orientations relatives à l'attribution de marchés dont la valeur est inférieure aux seuils fixés par l'UE (question 1).

1.2 Seuils nationaux applicables hors seuils européens et procédures de passation de marchés publics

dont la valeur est inférieure aux seuils (questions 2 et 3) ....................................................................15

1.3 Règles applicables en matière d'appels d'offres et de publication en dessous des seuils fixés par

l'UE (questions 4 et 5)....

1.4 Délais de présentation des demandes de participation et de soumission des offres (question 6)...18

1.5 Moyens de présentation des demandes de participation et de soumission des offres (question 7) 19

1.6 Politiques et règles applicables en matière de sélection qualitative (question 8)...

1.7 Politiques et règles applicables en matière d'examen des offres et de critères d'attribution, $\mathrm{y}$ compris les règles de détermination des offres anormalement basses (question 9) .................................20

1.8 Règles relatives au cahier des charges (question 10) ............................................................20

1.9 Politiques et règles applicables en matière de passation de marchés publics en ligne (question 11)20

1.10 Politiques et règles applicables en matière d'accords-cadres (question 12).............................21

1.11 Procédures en vigueur en matière de plaintes, de révision et de recours (question 13) ............21

PARTIE II RÈGLES ET PROCÉDURES COMMUNES NON COUVERTES EN DÉTAIL PAR

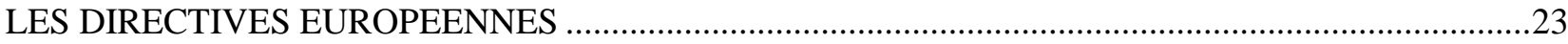

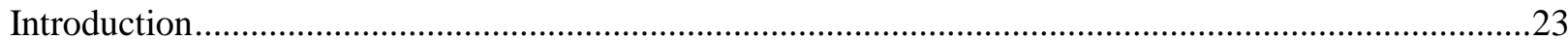

2.1 Organisation des procédures d'appel d'offres (question 14) .....................................................23

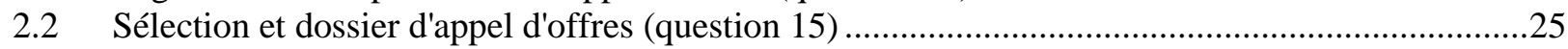

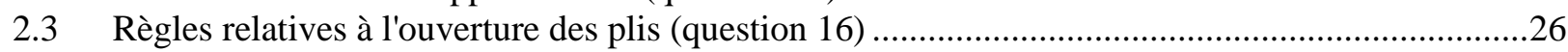

2.4 Règles relatives aux garanties d'adjudication et d'exécution (question 17) ...................................27

2.5 Règles relatives à l'annulation des procédures d'appel d'offres (question 18)..............................28

2.6 Règles relatives au délai de validité des offres (question 19) ...................................................29

2.7 Utilisation du système de la double enveloppe (question 20) ....................................................30

2.8 Règles relatives au conflit d'intérêt (question 21) .....................................................................30 
2.9 Règles particulières applicables à l'attribution de marchés de services de conseil et autres services

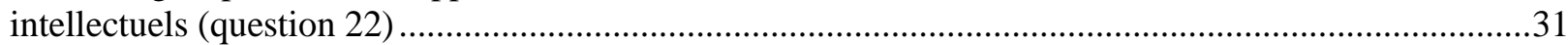

2.10 Changements de réglementation planifiés (question 23) ........................................................32

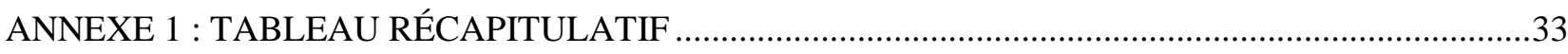

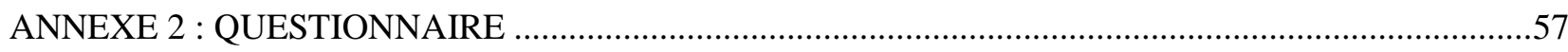




\section{NOTE DE SYNTHÈSE}

\section{Observations générales}

La passation des marchés publics dont le montant est inférieur aux seuils fixés par l'Union européenne s'est développée au point de représenter une part considérable de tous les marchés publics passés dans l'ensemble des États membres. La passation de ces marchés obéit aux procédures nationales applicables en la matière. Le nombre de marchés dont le montant est inférieur aux seuils fixés par l'UE dépasse largement le nombre des marchés dont la valeur excède ces seuils. Les marchés publics revêtent une importance toute particulière pour les petites et moyennes entreprises (PME). Il est de ce fait primordial d'encadrer et d'organiser l'adjudication de ces marchés de manière saine et efficace, en élaborant des politiques et des règles dédiées au niveau national. Seule l'observation des principes fondamentaux énoncés dans le Traité sur l'Union européenne est imposée par le droit européen dans la passation des marchés non couverts par les Directives. Il incombe donc aux États membres d'élaborer dans le détail les règles et autres procédures devant s'appliquer à ce type de marchés. Cependant, la présente étude prouve que la majorité des États membres se réfèrent à une seule et même loi pour encadrer la passation des marchés publics, que leur montant soit supérieur ou inférieur aux seuils fixés par l'UE, et exigent que les marchés dont le montant est inférieur aux seuils européens soient attribués dans le cadre de procédures ouvertes, équitables et concurrentielles. Ces procédures présentent essentiellement les mêmes caractéristiques que celles imposées en vertu des Directives européennes. Les États membres dépourvus de toute réglementation en ce sens favorisent toujours la soumission d'offres concurrentielles pour les marchés dont la valeur est inférieure aux seuils européens. Si le degré de simplification diffère d'un État membre à l'autre, l'objectif principal de garantir une mise en concurrence ouverte semble toutefois bien respecté, bien que les États membres aient le droit d'adopter des positions différentes sur les seuils pour contourner le droit régissant les marchés publics et pour autoriser les acquisitions directes. On entend normalement par simplification des délais de présentation des demandes de participation et de soumission des offres réduits, ainsi que des règles de publication et de sélection des soumissionnaires moins contraignantes. On observe dans certains cas l'application de règles plus souples quant au recours à des procédures négociées et à des adjudications directes mais, de manière générale, ces règles imposent également soit une obligation de publication préalable, soit un nombre minimal de soumissionnaires. Autrement, les règles relatives au cahier des charges, aux critères de sélection et d'attribution, de même que le droit de porter plainte sont essentiellement similaires, que les marchés soient inférieurs ou supérieurs aux seuils européens.

La première partie de cette publication abordera spécifiquement les règles et autres procédures qui s'appliquent aux marchés dont le montant est inférieur aux seuils fixés par l'UE. Il sera question dans la deuxième partie des règles et des procédures applicables à l'ensemble des marchés (indépendamment de leur valeur) qui ne sont pas traités en détail dans les Directives européennes mais qui sont tout aussi importants pour l'instauration d'un cadre procédural exhaustif au niveau national. Figurent notamment au nombre des domaines qui ne sont pas spécifiquement couverts par les Directives l'organisation des procédures de passation des marchés publics, la préparation et le contenu des dossiers d'appel d'offres, les délais de validité des appels d'offres, la soumission et l'ouverture des offres, les garanties d'adjudication et d'exécution, les modalités clarifiant avec détail les offres, ainsi que la suspension et l'annulation des offres.

Si cette étude ne permet pas de déterminer de manière probante le degré de variabilité de ces règles et autres procédures en fonction de la valeur du marché, qu'elle soit supérieure ou inférieure aux seuils européens, certains indices montrent que, dans les secteurs étudiés, les États membres, par souci de 
simplification, se dotent d'un régime plus souple pour les marchés dont la valeur est inférieure aux seuils fixés par l'UE.

Le fait qu'un État membre soit dépourvu de tout cadre légal régissant un domaine particulier abordé dans la présente étude ne saurait nullement signifier que la pratique opérationnelle de cette procédure ne soit ni mise en œuvre, ni réglementée. La question du conflit d'intérêt, qui est souvent encadrée par des lois particulières, indépendantes du droit relatif aux marchés publics, en est un parfait exemple.

La présente étude démontre dans la deuxième partie que les divergences entre les approches réglementaires adoptées par les États membres sur ces politiques et ces règles sont bien plus importantes que celles observées dans leurs approches sur les marchés dont la valeur est inférieure aux seuils européens. L'objet de la présente étude n'est pas d'expliquer pourquoi un État membre a adopté telle ou telle position, un débat hors sujet, mais bien de démontrer l'existence réelle de divergences entre les approches réglementaires adoptées par les États membres. Si ces divergences peuvent s'expliquer par des différences dans les politiques et les traditions régissant les systèmes juridiques et administratifs des États membres, elles peuvent également traduire une certaine position réglementaire de ceux-ci au moment de leur adhésion à l'UE. Les instruments réglementaires des nouveaux membres de l'UE (2004 et 2007) prévoient généralement des dispositions plutôt détaillées sur l'organisation et la conduite des procédures d'appels d'offres, que les pouvoirs adjudicateurs sont tenus d'observer pendant toute la durée du processus de passation des marchés publics. Cette situation détonne avec celle d'autres États membres où les pouvoirs et les entités adjudicatrices semblent disposer de plus de liberté quant à l'organisation des procédures d'appels d'offres. 


\section{Observations détaillées}

\section{Partie I. Règles et autres procédures d'intérêt particulier pour la passation de marchés dont la valeur est inférieure aux seuils fixés par l'UE}

La présente publication identifie les points suivants comme caractérisant essentiellement la façon dont les États membres réglementent la passation des marchés publics dont la valeur est inférieure aux seuils européens :

1) Une très grande majorité d'États membres contrôlent la passation des marchés publics dont la valeur est inférieure aux seuils européens au moyen de lois ou de réglementations, du moins dans le secteur traditionnel. Seuls le Royaume-Uni et l'Irlande ont recours à des documents d'orientation comme moyen unique pour informer les entités adjudicatrices de leurs obligations et des bonnes pratiques en vigueur dans la passation de marchés publics dont la valeur est inférieure aux seuils fixés par l'UE.

2) La plupart des États membres font explicitement référence aux principes du Traité de l'UE dans leurs réglementations.

3) Un grand nombre d'États membres appliquent indifféremment la même réglementation au secteur classique et aux secteurs dits spéciaux pour encadrer les marchés publics dont la valeur est inférieure aux seuils européens.

4) Cependant, un nombre considérable d'États membres interrogés ne disposent d'aucune réglementation pour contrôler la passation des marchés publics dans les secteurs spéciaux.

5) La réglementation portant sur les services Partie B se décline en diverses approches : certains États membres intègrent des règles similaires à celles applicables aux services Partie $\mathrm{A}$, tandis que d'autres proposent davantage de simplification ou se contentent de se référer aux principes du Traité.

6) La majorité des États membres dotés d'une réglementation ont établi deux, voire trois sous-seuils inférieurs aux seuils européens, qui diffèrent normalement selon le type de marché : seuils bas pour les marchés de fourniture et de services, et seuils plus élevés pour les marchés de travaux. Les fourchettes les plus basses déterminent si la réglementation s'applique ou si l'acquisition directe est autorisée. Le niveau suivant autorise l'usage de procédures simplifiées telles que des demandes de devis ou des adjudications directes ; ce seuil est normalement compris entre 50000 et 70000 EUR pour les marchés de fournitures et de services. Au-dessus de ce seuil national, nombreux sont les États membres à appliquer des règles et des procédures plus ou moins identiques à celles qui encadrent les marchés dont la valeur excède les seuils européens, à l'exception des règles nationales de publication et de la réduction des délais de présentation des demandes de participation et de soumission des offres.

7) L'adjudication directe est normalement autorisée dans le cadre de marchés de faible valeur, dont le seuil est généralement compris entre 5000 et 15000 EUR. Outre les variantes simplifiées des procédures visées dans les Directives européennes (ouvertes/restreintes/négociées), beaucoup d'États membres prévoient le recours à des procédures concurrentielles basées sur des appels d'offres directs avec publication préalable (par exemple, demandes d'appels d'offres ou de devis). D'autres États membres adoptent un régime plus souple prévoyant la possibilité de négocier avec publication préalable ou des procédures de mise en concurrence ouvertes.

8) La majorité des réglementations exigent de publier les marchés dont la valeur est inférieure aux seuils fixés par l'UE via des portails Web centraux, des bulletins spéciaux, des bases de données et les sites Web des entités adjudicatrices. Les conditions de publication s'appliquent aux avis de marchés et, dans certains cas, aux avis d'attribution de marchés également. Lorsque des 
procédures simplifiées sans publication sont autorisées, les réglementations exigent que les appels d'offres prévoient un nombre suffisant d'opérateurs économiques pour garantir la mise en concurrence.

9) La réduction des délais de présentation des demandes de participation et de soumission des offres est une méthode de simplification courante dans les États membres. Certains États membres n'imposent aucun délai et laissent ce choix aux entités adjudicatrices. Lorsque la réglementation applicable prévoit un délai minimum, ce qui est habituellement le cas, celui-ci est généralement de 10 à 15 jours pour les demandes de participation, et de 10 à 25 jours pour la soumission des offres. Ces délais peuvent souvent être réduits dans le cas de soumissions électroniques.

10) Il est intéressant de constater qu'un certain nombre de secteurs sont soumis à des règles et des procédures plus ou moins semblables à celles applicables aux marchés dont la valeur excède les seuils fixés par l'UE. Elles prescrivent :

- les moyens de présentation des demandes de participation et de soumission des offres ;

- l'examen des offres et les critères d'attribution, y compris les offres anormalement basses ;

- la préparation du cahier des charges ;

- les accords-cadres ;

- la passation de marchés publics en ligne.

11) La majorité des États membres dotés d'une réglementation appliquent des règles de réclamation, de révision et de recours analogues à celles applicables aux marchés dont la valeur excède les seuils européens.

\section{Partie II. Règles et procédures communes non couvertes en détail dans les Directives européennes}

Sont exposées ci-après les principales caractéristiques des dispositions adoptées par les États membres pour réglementer les secteurs qui ne sont pas traités en détail dans les Directives européennes et qui peuvent s'appliquer à tous les contrats de valeur supérieure comme inférieures aux seuils européens :

1) Un large groupe d'États membres précisent, de manière plus ou moins détaillée, dans leur réglementation sur la passation des marchés publics, la manière d'organiser la procédure d'appel d'offres au sein des entités adjudicatrices. La réglementation contient normalement des dispositions détaillées sur les responsabilités, la composition et les méthodes de travail des Comités ou des Commissions adjudicatrices (CA) instaurés à cette fin particulière. Il incombe habituellement à ces CA de : (i) préparer le dossier d'appel d'offres et d'émettre les appels d'offres avec le concours de l'organisme de tutelle ; (ii) gérer l'ouverture et l'évaluation des offres ; et (iii) d'émettre des recommandations sur l'attribution des marchés, exécutoire ou non, à l'attention de l'instance responsable au sein de l'organisme de tutelle.

2) Un second groupe d'États membres ne prévoient aucune réglementation quant à la manière d'organiser les procédures d'appel d'offres dans leurs règles de passation des marchés publics, ou ne traitent cette question que de manière très limitée. L'élaboration des procédures d'organisation et des méthodes de travail applicables à la passation des marchés publics incombe normalement aux entités adjudicatrices. D'autres actes administratifs ou réglementations internes peuvent prévoir des règles portant sur l'organisation de la procédure de passation des marchés publics. Cependant, ceux-ci dépassent le cadre de la présente étude.

3) La majorité des États membres incluent des informations détaillées sur le contenu du dossier d'appel d'offres, qui sont souvent obligatoires, mais ne prévoient aucune obligation quant à l'usage de documents types ou standard pour la sélection/qualification et les appels d'offres. 
Parfois, ils permettent également aux entités adjudicatrices de facturer des frais contre la remise du dossier d'appel d'offres. Cependant, cette règle semble être rarement appliquée dans le cas des délivrances électroniques. Enfin, un dernier groupe d'États membres ne prévoient aucune disposition à ce sujet, à l'exception de celles énoncées dans les Directives européennes.

4) Une majorité d'États membres exigent l'ouverture publique des plis indépendamment de leur valeur, ce qui signifie que l'ouverture publique s'applique également fréquemment aux marchés dont la valeur est inférieure aux seuils européens. D'autres États membres ne prévoient quant à eux aucune disposition à cet égard et laissent aux pouvoirs adjudicateurs le soin de décider des procédures à appliquer eu égard à l'ouverture des plis.

Si la majorité des États membres prévoient des dispositions sur les garanties d'adjudication et d'exécution pour les marchés dont la valeur est inférieure ou supérieure aux seuils européens, dans la plupart des pays, les décisions relatives à la mise en place et à l'importance de ces garanties sont laissées au soin du pouvoir adjudicateur. Cependant, certains États membres n'imposent pas l'utilisation de telles garanties pour les marchés dont la valeur est inférieure aux seuils fixés par l'UE. Un autre groupe d'États membres ne prévoient aucune disposition relative aux garanties et ne les exécutent que rarement, même lorsqu'elles sont autorisées.

5) La majorité des États membres prévoient des règles sur l'annulation des procédures d'appel d'offres, mais certains d'entre eux ne disposent que de règles limitées ou en sont totalement dépourvus, à l'exception de celles imposées par les Directives européennes.

6) La grande majorité des États membres ont réglementé, de manière plus ou moins détaillée, le délai de validité des appels d'offres, qui doit être précisé dans l'avis de marché ainsi que dans le dossier d'appel d'offres. Certains États membres ont même déterminé la durée maximale de validité des offres en nombre de jours, mais la plupart des pays laissent aux pouvoirs adjudicateurs le soin de déterminer la durée de validité. Enfin, un petit groupe d'États membres ne prévoit aucune disposition à cet égard.

7) Les États membres n'ont que rarement recours au système de la double enveloppe, de même qu'aux dispositions particulières régissant l'adjudication de services de consultance. Dans certains États membres, ces questions sont normalement réglementées dans le cadre de procédures normalisées.

8) De nombreux États membres disposent de règles sur le conflit d'intérêt dans le cadre de leur réglementation sur la passation des marchés publics, en particulier celles qui régissent l'organisation des procédures d'appels d'offres. Certains États membres traitent la question du conflit d'intérêt dans le cadre d'autres actes ou réglementations.

9) Seuls quelques États membres indiquent de possibles changements au niveau de leurs cadres réglementaires dans un avenir proche, à l'exception de ceux imposés par le droit européen. 


\section{MÉTHODOLOGIE}

La présente étude a été réalisée par l'équipe responsable du projet Sigma puis révisée par une équipe de confrères. Les données ont été recueillies à l'aide d'un questionnaire détaillé envoyé en 2009 aux interlocuteurs des vingt-sept États membres de l'UE. Cette étude reflète la situation des États membres à compter de juillet 2009. Tous les États membres abordés dans ce rapport ont eu la possibilité de faire part de leurs observations sur une version provisoire du rapport afin de valider les informations.

Les membres de l'équipe responsable du projet étaient M. Peter Bennett, M. Peder Blomberg, M. Yves Allain et M. Piotr-Nils Gorecki. L'équipe des confrères a été formée en vue de formuler des observations sur la méthodologie ainsi que sur le questionnaire et les versions provisoires et définitives du rapport. Cette équipe était composée de M. Michael Fruhmann (Autriche), de Mme Andrea Sundstrand (Suède) et de M. Peter Trepte (Royaume-Uni).

Le questionnaire détaillé préparé par Sigma a été envoyé aux organismes nationaux responsables de réglementer la passation des marchés publics dans les États membres, lesquels ont été priés de bien vouloir coopérer et répondre aux questions. Dans la mesure du possible, l'équipe responsable du projet et l'équipe des confrères ont analysé les informations fournies de manière à fournir un cadre de référence à la préparation de l'analyse comparative. Au total, 22 questionnaires ont été retournés à l'équipe du projet Sigma entre juillet et décembre 2009, par l'Autriche, la Bulgarie, Chypre ${ }^{3}$, la République tchèque, le Danemark, l'Estonie, la Finlande, la France, la Hongrie, l'Irlande, l'Italie, la Lettonie, la Lituanie, le Luxembourg, les Pays-Bas, la Pologne, la Roumanie, la Slovaquie, la Slovénie, l'Espagne, la Suède et le Royaume-Uni.

Il convient de clarifier un certain nombre de points eu égard aux limites de cette approche méthodologique. Les États membres de l'UE n'ont pas tous retourné le questionnaire. Par conséquent, la présente étude ne saurait nullement constituer un aperçu complet des cadres réglementaires mis en œuvre dans l'ensemble des États membres actuels. Cependant, le renvoi de 22 questionnaires sur 27 représente un taux de réponse positif pouvant servir de référence à une synthèse pertinente.

\section{$3 \quad$ Note de bas de page de la Turquie}

Les informations sur «Chypre» contenues dans le présent document se rapportent à la partie sud de l'île. L'île est dépourvue de toute autorité représentant à la fois les citoyens turcs et chypriotes grecs. La Turquie reconnaît la République turque de Chypre du Nord (RTCN). À moins qu'une solution durable et équitable ne soit trouvée dans le cadre des Nations Unies, la Turquie maintiendra sa position sur la question de «Chypre».

Note de bas de page rédigée par tous les États de l'Union européenne membres de l'OCDE et de la Commission européenne

La république de Chypre est reconnue par tous les membres des Nations Unies, à l'exception de la Turquie. Les informations contenues dans ce document se rapportent à la zone placée sous le contrôle effectif du Gouvernement de la république de Chypre. 


\section{PARTIE I. RÈGLES ET AUTRES PROCÉDURES D'INTÉRÊT PARTICULIER POUR LA PASSATION DE MARCHÉS DONT LA VALEUR EST INFÉRIEURE AUX SEUILS FIXÉS PAR L'UE}

\section{Introduction}

L'attribution des marchés publics dont le montant est inférieur aux seuils fixés par l'Union européenne revêt une importance considérable dans tous les États membres de l'UE.

Selon une évaluation des Directives relatives à la passation des marchés publics réalisée par Europe Economics pour la Commission européenne publiée en 2006, seuls $20 \%$ environ du nombre total de marchés publics ont été couverts par les règles détaillées des Directives, alors que le reste ferait l'objet d'exceptions à ces Directives, à l'instar par exemple de certaines acquisitions dans le domaine de la défense et de marchés dont la valeur est inférieure aux seuils européens.

Selon une communication interprétative (CI) de la Commission européenne, ces marchés offrent d'importantes opportunités aux entreprises sur le marché intérieur, plus particulièrement aux PME.

Il est de ce fait primordial d'encadrer et d'organiser de manière saine et efficace l'adjudication des marchés inférieurs aux seuils en élaborant des politiques et des règles dédiées au niveau national.

Les États membres ont élaboré leur propre cadre de politiques, de règles et de procédures applicables aux marchés dont la valeur est inférieure aux seuils européens sur la base d'un certain nombre d'arrêts prononcés par la Cour de justice européenne (CJE). Ces arrêts stipulent que les pouvoirs et les entités adjudicatrices qui concluent des marchés non couverts par les directives portant sur les marchés publics doivent, d'une manière générale, se conformer aux principes fondamentaux énoncés dans le Traité de l'UE et, plus particulièrement, au principe de non discrimination en raison de la nationalité, dès lors que ces marchés présentent un certain intérêt au niveau transfrontalier. Dans l'affaire Telaustria (arrêt C-324/98), portant sur des concessions de services, la CJE a invoqué l'obligation de transparence, qui permettrait au pouvoir ou à l'entité adjudicatrice de garantir son respect du principe de non discrimination, en ces termes :

« Cette obligation de transparence impose au pouvoir adjudicateur de garantir à chaque soumissionnaire potentiel un niveau adéquat de publicité permettant l'ouverture des marchés publics de services à la concurrence ainsi qu'un contrôle de l'impartialité de la procédure ».

En 2006, en réponse à des arrêts tels que l'arrêt Telaustria, la Commission européenne a rédigé une CI sur le droit communautaire applicable en matière de passation de marchés publics n'étant nullement soumis, ou seulement partiellement, aux dispositions des directives relatives à la passation des marchés publics. Il est précisé dans cette CI que les principes fondamentaux du Traité s'appliquent à tous les marchés publics, notamment aux marchés portant sur la prestation de services Partie B et dont le montant est inférieur aux seuils fixés par l'UE. Dans cette CI, la Commission souligne qu'il est impératif, aux fins de respecter les obligations du Traité, de prendre en considération la pertinence des marchés spécifiques pour le marché intérieur au moment de déterminer la nature de la publicité ainsi que les autres procédures à suivre. Une position confirmée par la suite dans l'affaire An Post (C-507/03, le 13 novembre 2007).

Prière de consulter le tableau récapitulatif en Annexe 1 pour des informations détaillées. 


\subsection{Instrument(s) réglementaire(s) ou orientations relatives à l'attribution de marchés dont la valeur est inférieure aux seuils fixés par l'UE (question 1)}

Cette question visait à obtenir des informations sur la manière dont les États membres élaborent un cadre législatif ou émettent des orientations quant aux modalités d'attribution des marchés dont la valeur est inférieure aux seuils européens par les pouvoirs et les entités adjudicatrices. Sur les 22 États membres ayant répondu, seuls le Royaume-Uni et l'Irlande ont exclusivement recours à des orientations pour informer les acquéreurs de leurs obligations lorsqu'ils passent des marchés publics dont la valeur est inférieure aux seuils européens. Les Pays-Bas ont opté pour un système de réglementations et d'orientations non contraignantes. Tous les autres États membres se sont dotés d'un régime encadrant les marchés dont la valeur est inférieure aux seuils européens par le biais soit de réglementations couvrant les exigences relatives aux marchés supérieurs aux seuils, soit de réglementations nationales, soit d'une association des deux.

Les Directives relatives à la passation des marchés publics (2004/18/CE et 2004/17/CE) stipulent que toute attribution de marchés publics doit respecter les principes du Traité, notamment les principes de la libre circulation des marchandises, de la liberté d'établissement et de la libre prestation de services, ainsi que les principes qui en découlent, comme l'égalité de traitement, la non-discrimination, la reconnaissance mutuelle, la proportionnalité et la transparence. La plupart des États membres se réfèrent aux obligations du Traité, de manière explicite ou tacite, dans leurs réglementations respectives, à l'exception de la Hongrie, du Luxembourg et des Pays-Bas. La République tchèque intègre les obligations du Traité à la seule attention des pouvoirs adjudicateurs. Les États membres reprennent le plus fréquemment dans leur droit interne les principes de l'égalité de traitement, de la non-discrimination et de la transparence. La Finlande se réfère bien à ces trois principes dans le seul but, toutefois, de répondre aux besoins de proportionnalité des pouvoirs adjudicateurs.

Dans leur élaboration de règles détaillées encadrant les marchés de valeur inférieure aux seuils européens, les États membres auront tenu compte du traitement qu'ils comptent réserver à de tels marchés dans le secteur dit classique, dans les secteurs spéciaux ainsi que pour les services Partie B (c.-à-d. les services qui ne sont pas couverts par l'ensemble des règles imposées par les directives). La plupart des États membres reprennent les réglementations relatives aux marchés dont la valeur est supérieure aux seuils européens pour encadrer les marchés de valeur inférieure aux seuils de l'UE dans le secteur public. La Bulgarie a, en outre, établi une réglementation pour les marchés de faible valeur, intitulée Small Contracts Ordinance (OASPC). Les réglementations danoises applicables aux marchés de valeur inférieure aux seuils européens ayant pour objet des travaux (2005), et des fournitures et des services (2007) sont distinctes de la loi d'exécution des directives européennes. Les Pays-Bas disposent de réglementations régissant les secteurs spéciaux ainsi que les travaux dans le secteur classique, que les pouvoirs et les entités adjudicatrices sont tenues de suivre.

Huit États membres dans lesquels la passation de marchés de valeur inférieure aux seuils européens est réglementée appliquent la même réglementation pour le secteur public et les secteurs spéciaux : l'Autriche, la Bulgarie, la France, la Hongrie, l'Italie, la Lituanie, le Luxembourg et la Roumanie. La Slovénie, l'Espagne et la Suède disposent de règles régissant les marchés de valeur inférieure aux seuils européens dans leurs réglementations respectives sur les secteurs spéciaux. Huit États membres, à savoir la République tchèque, Chypre, le Danemark, l'Estonie, la Finlande, la Lettonie, la Pologne et la Slovaquie, ne disposent d'aucune disposition particulière pour réglementer les marchés dont la valeur est inférieure aux seuils européens dans les secteurs spéciaux. Ces marchés sont régis dans le cadre d'un ou de plusieurs actes distincts. Bien que le Danemark ne se soit doté d'aucune réglementation, les entités adjudicatrices sont tenues d'établir des réglementations internes. Comme indiqué plus haut, la réglementation relative aux secteurs dits spéciaux n'est pas contraignante aux Pays-Bas. 
S'agissant des services Partie B, les États membres adoptent diverses approches variées, aucun n'ayant de loi spécifique exclusivement applicable à ces services. Dans le détail, les procédures encadrant la passation des marchés de services Partie B dont le montant est inférieur aux seuils européens doivent être étudiées à la lumière de ce qui a déjà été énoncé, à savoir que certains États membres se contentent d'établir des règles régissant les marchés de valeur inférieure aux seuils européens dans le secteur classique, alors que d'autres ne font pas explicitement référence aux obligations du Traité dans leurs réglementations. L'Italie observe l'approche visée dans les directives européennes en matière de marchés excédant les seuils européens en adoptant des règles relatives au cahier des charges et aux avis d'attribution des marchés. Les services Partie B peuvent être attribués via une procédure dite négociée sans avis préalable, sous réserve d'exiger le devis d'au moins cinq soumissionnaires. Une approche simplifiée de la réglementation sur les marchés de valeur inférieure aux seuils européens est également adoptée par l'Autriche dans ce qui semble être un régime très souple, par la France, où une procédure appropriée doit être suivie, par la Pologne, qui a choisi d'ignorer de nombreuses dispositions détaillées imposées par sa réglementation, par la République tchèque, qui autorise le recours à la procédure négociée, et par le Danemark, qui exige de faire suivre toute publicité par des négociations. Figurent parmi les États membres ayant adopté une approche plus structurée la Suède, qui requiert soit une procédure ouverte simplifiée, soit une procédure simplifiée en deux étapes, comprenant la possibilité de négocier dans le cadre de l'une ou l'autre de ces deux procédures, et l'Estonie, où une procédure publique doit être observée dans le cas de marchés dont la valeur excède le seuil national. La Finlande, la Lituanie et la Slovénie appliquent les mêmes règles pour les marchés de valeur inférieure comme supérieure aux seuils européens dès lors que la valeur du marché excède les seuils nationaux, bien que la Finlande autorise une certaine flexibilité quant au recours aux procédures négociées. Chypre exige que les règles applicables aux marchés de services Partie B dont la valeur est supérieure aux seuils européens soient suivies, quelle que soit la valeur du marché.

\subsection{Seuils nationaux applicables hors seuils européens et procédures de passation de marchés publics dont la valeur est inférieure aux seuils (questions 2 et 3 )}

Afin d'obtenir une vue d'ensemble complète des obligations qui incombent aux pouvoirs et aux entités adjudicatrices, le rapport s'est attaché à analyser en parallèle les réponses données sur les seuils et les procédures. Si certains États membres ont fixé trois fourchettes ou plus de valeurs inférieures aux seuils européens, la plupart d'entre eux en établissent deux, avec un seul seuil national, en dessous duquel il y a appel d'offres direct et au-dessus duquel les règles ne sont pas aussi rigoureuses que le régime imposé par l'UE. La Slovénie décrit parfaitement l'objectif poursuivi par l'établissement de ces seuils et des procédures qui s'y rapportent dans les termes suivants : «pour aligner les procédures d'attribution en fonction de l'objet du marché, et notamment de la valeur estimée du marché conformément au principe de proportionnalité ».

Le point de départ des seuils nationaux en dessous desquels les appels d'offres sont directs peut varier considérablement. En Bulgarie, à Chypre, en Finlande, en France, en Lettonie, en Pologne, en Roumanie et en Slovénie, la limite s'élève à 15000 EUR ou moins, alors qu'en Italie, en Hongrie, en Lituanie et en Slovaquie, elle est comprise entre 20000 et 30000 EUR. L'Autriche a fixé un point de départ à 40000 EUR, au même titre que l'Estonie, le Luxembourg à 55000 EUR, le Danemark à 67000 EUR, et la République tchèque à 70000 EUR.

La Bulgarie, Chypre, la Roumanie, la Slovénie et la Slovaquie ont établi trois fourchettes ou plus pour l'attribution des marchés de valeur inférieure aux seuils imposés, y compris une fourchette pour les appels d'offres directs. Ces pays déterminent une ou plusieurs fourchettes pour l'application des procédures simplifiées. Les seuils applicables aux marchés de fournitures et de services dans le secteur classique sont établis comme suit. À Chypre, les procédures simplifiées s'appliquent à deux sous-fourchettes comprises entre 1700 et 8500 EUR et entre 8500 et 85000 EUR (approximativement). La sous-fourchette la plus basse impose de restreindre le nombre d'offres écrites ou orales déposées par les soumissionnaires ; dans la sous-fourchette la plus haute, aucune prépublication n'est exigée, mais les documents contractuels doivent 
être envoyés au moins à quatre fournisseurs choisis en toute objectivité. Dans le cadre de sa procédure simplifiée, Chypre vise à accélérer la procédure et à réduire les coûts de gestion. Pour les marchés tombant dans une fourchette comprise entre 15000 et 100000 EUR, la Roumanie impose le recours à des demandes de devis (procédure simplifiée). Pour une fourchette comprise entre 10000 et 40000 EUR, le droit slovène exige la réception de 3 offres, sans publication préalable, même si les pouvoirs ont l'intention d'imposer également une publicité préalable à cette fourchette de marchés. En vertu de la Small Contracts Ordinnance (OASPC), trois offres doivent être au moins reçues pour les marchés de fournitures et de services dont la valeur est comprise dans une fourchette de 8000 à 25000 EUR. La Roumanie applique les règles européennes pour les marchés dont la valeur dépasse le seuil de 100000 EUR. Si les règles européennes peuvent également s'appliquer en Slovénie au-delà d'un seuil de 40000 EUR, les pouvoirs adjudicateurs ont la possibilité de recourir à une procédure simplifiée dans une fourchette de valeur comprise entre 40000 et 80000 EUR, ce qui les autorisent à solliciter des offres dans le cadre d'un avis préalablement publié sur le portail national. La procédure simplifiée peut se dérouler en une ou deux étapes, mais reste moins onéreuse aussi bien pour les acheteurs que pour les soumissionnaires.

La Lettonie a fixé deux sous-seuils en dessous desquels l'acquisition directe est autorisée : 4500 EUR (pour les marchés de fournitures et services) et 14000 EUR (pour les marchés de travaux). Au-dessus de ces sous-seuils et jusqu'à respectivement 30000 et 170000 EUR, une procédure concurrentielle simplifiée peut être utilisée. Au-dessus de ces seconds sous-seuils, les procédures et autres règles (à l'exception de délais plus courts) applicables sont identiques à celles régissant les marchés supérieurs aux seuils fixés par l'UE. La passation des marchés publics dans les secteurs spéciaux ne fait l'objet d'aucune réglementation.

L'Autriche a fixé des sous-seuils au-dessus desquels des procédures particulières deviennent disponibles. S'agissant des marchés de fournitures et de services, une procédure négociée sans publication est autorisée jusqu'à 60000 EUR, une procédure restreinte sans publication peut être applicable jusqu'à 80000 EUR, et une procédure négociée avec publication préalable est consentie à hauteur des seuils fixés par l'UE.

Certains États membres disposent d'un seuil national unique pour les marchés de fournitures et de services. Un nombre restreint de ces pays imposent l'observation des règles de l'UE, dans la limite d'une simplification restreinte, au-dessus de ces seuils, tandis que d'autres ne prescrivent aucune procédure à suivre. Les pays suivants appliquent généralement les procédures européennes, avec quelques rares variantes, au-delà des seuils prescrits : La Pologne (14 000 EUR), l'Italie (20 000 EUR où, en dehors des marchés de travaux et de certains marchés énumérés dans la loi, une demande de devis auprès de cinq fournisseurs est autorisée) et la République tchèque (70 000 EUR).

La Hongrie impose une obligation de publication pour les marchés dont la valeur excède 27000 EUR et autorise les négociations si celles-ci sont prévues dans l'avis du marché concerné. La Lituanie exige la publicité obligatoire pour les marchés dont la valeur excède 30000 EUR (pour les fournitures et les services) et 145000 EUR (pour les travaux), mais il n'existe aucune procédure définie à suivre. Seule la Hongrie a établi un seuil (83 000 EUR) pour les concessions de service, et le Danemark prévoit des procédures informelles à suivre au-dessus d'un seuil de 67000 EUR. En Suède, lorsque les marchés ne portent pas sur un montant de faible valeur (celle-ci n'étant pas définie par un seuil monétaire), ils doivent être annoncés puis suivis d'une procédure ouverte simplifiée ou d'une procédure simplifiée en deux étapes. En Espagne, le seuil national a pour objet d'indiquer le recours possible ou non à une procédure négociée, alors qu'aux Pays-Bas, les réglementations sont appliquées sur une base volontaire. En France, au-dessus d'un seuil de 90000 EUR, une publicité doit paraître au bulletin officiel. En dessous de ce seuil, les pouvoirs adjudicateurs sont libres de choisir la procédure la plus appropriée selon la nature et les caractéristiques des besoins à couvrir et le nombre ou l'implantation géographique des opérateurs économiques susceptibles de répondre à ces besoins. Les procédures de publication et de concurrence doivent être à la mesure de l'objet et de la valeur du marché. 
Le seuil minimal applicable aux marchés de travaux dans le secteur classique est habituellement au moins deux fois plus élevé que celui applicable aux marchés de fournitures et de services. Dès lors qu'il existe plus de deux fourchettes, celles qui couvrent les procédures simplifiées sont habituellement plus étendues. Par exemple, en Roumanie, la fourchette dans laquelle les demandes d'appels d'offres sont imposées varie entre 15000 et 750000 EUR pour les marchés de travaux et entre 15000 et 100000 EUR pour les marchés de fournitures et de services. Une approche prévisible étant donné que le seuil prévu par les directives pour les marchés de travaux est de 5 millions EUR. Seule la Hongrie a fixé un seuil distinct (333 000 EUR) pour les concessions de travaux.

Le Danemark, l'Italie et le Luxembourg ont adopté des approches différentes s'agissant des procédures applicables aux marchés de travaux et aux marchés de fournitures et de services. Au Danemark, des procédures ouvertes simplifiées ou restreintes sont imposées aux termes de la réglementation encadrant les marchés de travaux dont la valeur excède 40000 EUR. En Italie, une demande de devis (au nombre de cinq au moins) est autorisée en dessous de 200000 EUR, une procédure négociée sans publication en dessous de 500000 EUR, et une procédure restreinte simplifiée en dessous de 750000 EUR. Le Luxembourg permet de recourir à une procédure restreinte pour les marchés dont la valeur excède 800000 EUR, seuil en dessous duquel une procédure ouverte est autorisée.

Comme indiqué plus haut, peu de pays se sont dotés d'un régime pour encadrer les marchés de valeur inférieure aux seuils imposés dans les secteurs spéciaux. La Bulgarie, la Lituanie, le Luxembourg et la Roumanie adoptent une approche similaire à celle des seuils et des procédures observées dans le secteur public. En Roumanie, la fourchette la plus élevée s'étend jusqu'à 400000 EUR, reflétant le seuil minimal le plus élevé prévu par la directive relative aux secteurs spéciaux. L'Italie a établi le même seuil minimal. En Autriche, le seuil minimal est deux fois plus élevé que celui appliqué dans le secteur public, alors que la Hongrie l'a établi à 167000 EUR, contre 27000 EUR pour le secteur public. Il peut paraître surprenant, étant donné les règles plus souples dont bénéficient les secteurs spéciaux, qu'il n'y ait que très peu d'écart entre les régimes applicables aux marchés inférieurs aux seuils imposés adoptés par les États membres. Là encore, seul un nombre limité de pays ont établi des réglementations couvrant les exigences relatives aux marchés de valeur inférieure aux seuils imposés.

\subsection{Règles applicables en matière d'appels d'offres et de publication en dessous des seuils fixés par l'UE (questions 4 et 5)}

Certains États membres ont répondu aux questions 4 et 5 en même temps. En règle générale, les réponses ont porté sur la publication des avis (question 4), et sur l'utilisation de formulaires standards ou de variantes de ces formulaires (question 5).

Les avis de marché sont publiés dans les publications officielles (version papier) en Autriche, à Chypre, en Italie, en Lituanie et en Espagne. Tous ces pays, sauf l'Espagne, publient également des avis sur les portails ou les sites Web nationaux. La Bulgarie, la République tchèque, la Finlande, la Hongrie, la Lettonie, le Luxembourg, la Roumanie et la Slovaquie publient exclusivement leurs avis sur les portails en ligne nationaux et/ou sous forme électronique. En Roumanie, près de 66000 appels d'offres ont été publiés par les pouvoirs/entités adjudicatrices sur le système électronique des marchés publics (ESPP) en 2008. En Pologne, les pouvoirs adjudicateurs sont également tenus de publier des avis sur leurs sites Web pour les marchés aussi bien de valeur supérieure qu'inférieure aux seuils nationaux.

Au Danemark, la réglementation impose des conditions pour les avis concernant les marchés de biens et de services, mais il n'existe aucune règle spécifique de publication, qui s'effectue soit en ligne, soit dans les journaux. En France, les pouvoirs/entités adjudicatrices peuvent, en dessous d'un seuil de 90000 EUR, choisir les modalités de publication ; au-dessus de ce seuil, les avis doivent être publiés par les pouvoirs publics dans le bulletin officiel (BOAMP) ou dans un journal habilité à publier les avis légaux. Aux Pays- 
Bas, les pouvoirs adjudicateurs peuvent choisir le support de publication qui est généralement leur propre site Web. En Suède, une publication gratuite sur des «bases de données généralement reconnues » est requise.

Les règles applicables aux secteurs spéciaux sont similaires en Autriche, en Bulgarie, à Chypre, en Estonie, en France, en Lituanie, au Luxembourg et en Suède.

Certains pays (Chypre, la République tchèque, l'Estonie et la Lettonie) ont recours aux formulaires standards utilisés pour les marchés supérieurs aux seuils pour les marchés dont la valeur est inférieure aux seuils. En Hongrie, les formulaires standards des avis sont réglementés par décret du Ministre de la Justice, mais ils restent très semblables aux formulaires standards de l'UE. Le Luxembourg utilise des formulaires standards simplifiés sur son portail (portail du ministère des travaux publics sur lequel tous ses avis sont publiés). La Roumanie emploie également un format standard simplifié. La Bulgarie utilise un formulaire standard approuvé par le Ministère de l'économie, de l'énergie et du tourisme semblable aux formulaires normalisés de l'UE. En France, le format standard exigé pour la procédure appropriée est annexé à un arrêté ministériel de 2006. En Suède, seuls les avis de marchés doivent être publiés. Outre les avis de marchés, les pouvoirs et les entités adjudicatrices lituaniennes sont tenues de publier des rapports sur la procédure de passation des marchés publics sur le portail central.

Les règles applicables aux secteurs spéciaux sont similaires en Bulgarie, à Chypre, en Estonie, en France, en Hongrie, en Lituanie, au Luxembourg, en Roumanie et en Suède.

Le Danemark et les Pays-Bas disposent de règles limitées voire d'aucune règle en matière de publication.

\subsection{Délais de présentation des demandes de participation et de soumission des offres (question} 6)

Généralement, les États membres réduisent considérablement les délais de soumission pour les marchés de valeur inférieure aux seuils par rapport aux marchés dont la valeur excède ces seuils. Dans le cadre d'une procédure ouverte, le délai le plus courant est d'une vingtaine de jours, mais peut être compris entre 14 et 30 jours. Dans le cadre de procédures restreintes (et négociées), le délai le plus courant pour présenter les demandes de participation est de 10 jours. Le délai habituel pour la réception des offres dans le cadre d'une procédure restreinte est d'une quinzaine de jours. La Pologne applique des délais différents pour les marchés de travaux : 20 jours dans le cadre de la procédure ouverte contre 7 pour les marchés de fournitures et de services, et 14 jours dans le cadre de la procédure restreinte pour recevoir les offres de travaux, contre 7 jours pour les marchés de fournitures et de services. La Lettonie a fixé un délai de 30 jours pour la soumission des offres dans le cadre d'une procédure ouverte et de 25 jours en cas de procédure restreinte. En dessous de cette première fourchette, le délai est réduit à 15 jours. En Lituanie, le délai de soumission des offres dans le cadre d'une procédure ouverte est fixé à 7 jours à compter de la date de publication. Certains pays réduisent ces délais en cas de transmission par voie électronique. Par exemple, en Roumanie, les délais peuvent être ramenés de 20 à 15 jours dans le cadre d'une procédure ouverte, et de 15 à 10 jours pour la réception des offres dans le cadre d'une procédure restreinte.

En Bulgarie, les délais applicables aux contrats dont la valeur est inférieure aux seuils imposés par la loi relative à la passation des marchés publics suivent en grande partie les délais prévus dans les directives. L'Estonie observe également des délais identiques à ceux applicables aux marchés supérieurs aux seuils, aussi bien dans le secteur public que dans les secteurs spéciaux. En Slovénie, les pouvoirs adjudicateurs peuvent décider des délais, en prenant en considération la complexité du projet. Ils peuvent également appliquer les délais imposés par l'UE, bien que dans la pratique, ces délais soient plus courts, autorisant le principe de proportionnalité. En France, le choix des délais incombe généralement aux pouvoirs adjudicateurs, mais les délais doivent être suffisamment longs pour permettre au plus grand nombre 
d'opérateurs économiques de soumettre leurs offres. La Finlande et les Pays-Bas n'imposent aucune règle en matière de délais.

\subsection{Moyens de présentation des demandes de participation et de soumission des offres (question 7)}

Lorsque des règles existent, les demandes de participation et les offres peuvent respectivement être déposées et soumises par courrier, par fax ou par tout autre moyen électronique. Cependant, la nécessité de posséder les équipements techniques appropriés et de garantir la sécurité et la confidentialité est primordiale. Certains pays disposent de réglementations distinctes couvrant la transmission électronique, comme notamment la Bulgarie avec la Loi sur les supports et la signature électroniques. La République tchèque exige que les demandes de participation formulées par voie électronique soient assorties de signatures électroniques autorisées. En Espagne, le dossier d'appel d'offres est en général remis dans des enveloppes scellées à une adresse désignée ou est autrement adressé par courrier, à moins que les documents de soumission n'autorisent une autre procédure. En Roumanie, la transmission se fait habituellement sous format papier, mais le pouvoir/l'entité adjudicatrice peut spécifier des moyens électroniques. La Lettonie applique des règles de transmission des demandes de participation et des offres similaires à celles portant sur les marchés supérieurs aux seuils européens.

Le Danemark et les Pays-Bas ne disposent d'aucune disposition juridique spécifique, et il appartient aux pouvoirs et autres entités adjudicatrices de définir les moyens de transmission. La France ne possède à cette date aucune disposition juridique, mais les pouvoirs peuvent imposer une transmission par voie électronique. Néanmoins, depuis le $1^{\mathrm{er}}$ janvier 2010, les documents demandés aux candidats doivent être soumis via des moyens électroniques pour les marchés d'équipement informatique et les marchés de services excédant les 90000 EUR. À compter du $1^{\mathrm{er}}$ janvier 2012, les pouvoirs adjudicateurs ne seront plus en mesure de refuser les documents envoyés électroniquement pour les marchés de fournitures, de services ou de travaux d'une valeur supérieure à 90000 EUR.

\subsection{Politiques et règles applicables en matière de sélection qualitative (question 8)}

Les États membres suivants ont essentiellement adopté les mêmes réglementations pour les marchés dont la valeur excède ou est inférieure aux seuils imposés : l'Autriche, la Bulgarie, Chypre, la République tchèque, le Danemark, l'Estonie, la Hongrie, la Lettonie, la Lituanie, le Luxembourg, les Pays-Bas, la Pologne, la Slovaquie et la Suède. La principale différence avec les dispositions du régime applicable aux marchés supérieurs aux seuils concerne l'obligation d'apporter la preuve des qualifications. En République tchèque, les opérateurs économiques peuvent fournir la preuve de leurs qualifications sous forme de déclaration, sans avoir à fournir de documents spécifiques. En Pologne, les pouvoirs adjudicateurs ne sont pas tenus de demander des documents confirmant que les opérateurs économiques remplissent les conditions de participation. La Slovénie a simplifié la présentation des preuves dans un souci de réduire les lourdeurs administratives. Les opérateurs économiques ne sont nullement tenus de fournir une preuve pour laquelle les pouvoirs publics détiennent des données. Il appartient aux pouvoirs adjudicateurs d'obtenir ces données.

En Finlande, les principes employés pour encadrer les dispositions relatives aux marchés inférieurs aux seuils s'alignent sur ceux applicables aux marchés dont la valeur excède ces seuils. Si le droit français ne prévoit aucune disposition spécifique, les responsables des marchés publics ne sont pas autorisés à demander plus d'informations que pour les marchés dont la valeur excède les seuils. En Italie, le niveau d'exigences économiques et techniques est établi par le droit dérivé. En Roumanie, les pouvoirs et les entités adjudicatrices devraient, d'un point de vue pratique, définir des critères de qualification. Ils peuvent introduire un ou plusieurs des critères applicables aux marchés dont la valeur excède les seuils ou ne rien exiger de plus. 


\subsection{Politiques et règles applicables en matière d'examen des offres et de critères d'attribution, $y$ compris les règles de détermination des offres anormalement basses (question 9)}

Le choix des critères d'attribution prévu dans les directives relatives à la passation des marchés publics se fonde soit sur l'offre économiquement la plus avantageuse (OEPA), soit sur le prix le plus bas. La plupart des États membres prévoient également ce choix pour les marchés inférieurs aux seuils. Figurent au nombre de ces états l'Autriche, la Bulgarie, Chypre, l'Estonie, la Finlande, la Hongrie, l'Italie, la Lettonie, la Lituanie, la Pologne, la Roumanie, la Slovénie, la Slovaquie et la Suède. En Suède, la pondération des critères pour déterminer l'offre économiquement la plus avantageuse n'est pas obligatoire ; les critères peuvent être classés par ordre décroissant. La Finlande observe en grande partie l'approche relative aux marchés dont la valeur excède les seuils pour les marchés inférieurs aux seuils, mais l'étendue des critères d'évaluation pour certains marchés de services ou de travaux est plus large par rapport à celle des marchés en dessous des seuils. L'expertise, la capacité et les compétences professionnelles des personnes chargées de fournir le service ou d'accomplir les travaux peuvent être utilisées comme critères d'attribution ainsi que pour répondre à des critères minimaux de sélection. La France ne dispose d'aucune règle spécifique concernant les procédures appropriées utilisées par les pouvoirs et les entités adjudicatrices en dessous des seuils applicables, mais les actions du responsable des marchés publics sont encadrées par la jurisprudence.

Concernant les offres anormalement basses, une majorité d'États membres suivent les règles des directives, ou omettent de prescrire des règles spécifiques. Au Luxembourg, si une offre est $15 \%$ inférieure au prix moyen, l'opérateur économique est tenu de produire une analyse des prix. Si cette analyse ne permet pas de justifier l'offre basse, celle-ci peut être rejetée. L'Italie applique une méthode mathématique pour déterminer les offres anormalement basses. En outre, si plus de 10 offres sont soumises, les offres anormalement basses peuvent être automatiquement exclues en dessous d'un seuil fixé à 1 million EUR pour les marchés de travaux et à 100000 EUR pour les marchés de fournitures et de services.

\subsection{Règles relatives au cahier des charges (question 10)}

Presque tout les pays disposent de règles similaires pour encadrer le cahier des charges des marchés supérieurs comme inférieurs aux seuils. Le Ministère des finances estonien prescrit quant à lui des orientations complémentaires. En Suède, les règles applicables aux marchés dont la valeur est supérieure comme inférieure aux seuils sont en partie similaires. En dessous des seuils applicables, leur législation renvoie à l'article 23, paragraphes 6 et 8 de la Directive 2004/18/EU. Ces paragraphes portent sur les spécifications relatives aux caractéristiques environnementales sans prescrire de marque ou de source particulière.

\subsection{Politiques et règles applicables en matière de passation de marchés publics en ligne (question 11)}

L'Autriche, Chypre, la République tchèque, la Finlande, le Luxembourg, la Lettonie, la Roumanie, la Slovénie, la Slovaquie et la Suède observent des règles identiques pour la passation en ligne de marchés publics supérieurs et inférieurs aux seuils européens.

La Bulgarie prévoit l'utilisation d'enchères en ligne et de systèmes d'acquisition dynamiques dans sa loi sur la passation des marchés publics sous certaines règles et conditions. En outre, la Small Value Ordinance (OASPC) stipule que les pouvoirs et les entités adjudicatrices peuvent recourir à des enchères électroniques dans le cadre de concours dont le cahier des charges est clairement défini. En Estonie, tous les avis sont disponibles sur le registre électronique central, dans lequel il est prévu d'intégrer des enchères électroniques ainsi que des systèmes d'acquisition dynamiques. La France prescrit des dispositions juridiques concernant les procédures appropriées ayant recours à la transmission électronique qui doivent prendre en considération les caractéristiques du marché (en particulier l'objet et le volume des travaux, des 
fournitures ou des services), sans restreindre la concurrence. Les responsables des marchés publics peuvent exiger la transmission électronique et rejeter les réponses qui ne sont pas envoyées électroniquement. Cette règle s'applique à toutes les procédures depuis début 2010. Les procédures électroniques sont réglementées en détail dans un décret gouvernemental venant compléter les règles générales prescrites par la Loi sur la passation des marchés publics. La loi lituanienne sur la passation des marchés publics oblige les pouvoirs adjudicateurs à gérer au moins $50 \%$ des marchés publics électroniquement. La Pologne propose quant à elle une option permettant de recourir à une procédure d'enchère électronique particulière, qui ne s'exerce toutefois qu'en dessous des seuils fixés par l'UE. La procédure est initiée par le pouvoir adjudicateur via la publication d'un avis sur son site Web ainsi que sur le site Web du bulletin de marchés publics. Les opérateurs économiques peuvent alors remplir le formulaire en ligne pour soumettre des offres successives et plus avantageuses.

L'Italie a adopté une réglementation sur la passation des marchés publics en ligne en 2002, qui autorise le secteur public à passer des marchés inférieurs aux seuils imposés (sauf les marchés de travaux) via une plate-forme de passation de marchés publics en ligne (MEPA) établie par l'organisme acquéreur central italien (CONSIP). Le marché est ouvert aux fournisseurs qualifiés sur la base de critères de sélection non restrictifs. À l'issue de la qualification, les catalogues des fournisseurs sont téléchargés sur la MEPA puis présentés sur un site Web dédié, où ils deviennent accessibles à la communauté toute entière. Les pouvoirs adjudicateurs peuvent passer en revue les catalogues, comparer les produits et les prix, et demander des devis ou acheter directement sur le catalogue en ligne. Tout le processus transactionnel est numérique et requiert des signatures numériques.

\subsection{Politiques et règles applicables en matière d'accords-cadres (question 12)}

La plupart des États membres appliquent une approche similaire en matière d'attribution d'accords-cadres que ce soit pour les marchés inférieurs comme supérieurs aux seuils européens. Figurent au nombre de ces États membres l'Autriche, la Bulgarie, Chypre, l'Estonie, la Finlande, l'Italie, la Lettonie, le Luxembourg, la Pologne, l'Espagne, la Roumanie, la Slovaquie et la Suède. L'Autriche autorise la conclusion d'accordscadres en dessous des seuils en ce qui concerne les marchés de travaux dont la valeur n'excède pas 350000 EUR, dans le cadre d'une procédure négociée avec publication préalable d'un avis. Cette approche ne s'applique qu'aux marchés de travaux dont la valeur ne dépasse pas ce seuil. La Slovénie, quant à elle, autorise le recours à des procédures simplifiées selon les valeurs seuil. En Hongrie, la décision de conclure des accords cadres incombe au pouvoir adjudicateur. La France, le Danemark et la Lituanie ne prévoient aucune disposition particulière. Le Danemark observe également les procédures établies dans les directives relatives à la passation des marchés publics pour les marchés inférieurs seuils imposés ainsi que pour marchés de services Partie B.

\subsection{Procédures en vigueur en matière de plaintes, de révision et de recours (question 13)}

Dans le chapitre consacré à la protection juridique, la CI de la Commission européenne sur le droit communautaire applicable en matière de passation de marchés publics n'étant nullement soumis, ou seulement partiellement, aux dispositions des directives relatives à la passation des marchés publics stipule que les recours disponibles doivent être au moins aussi efficaces que ceux exercés dans le cadre de plaintes similaires fondées sur le droit national (principe d'équivalence), et ne doivent pas rendre impossible ou excessivement difficile l'obtention d'une protection juridique (principe d'efficacité).

Les pays qui réglementent les marchés inférieurs aux seuils n'établissent aucune distinction substantielle quant aux recours applicables en dessous et au-dessus des seuils. Naturellement, plus le régime relatif aux marchés inférieurs aux seuils est détaillé, plus le risque de porter plainte est élevé. Les pays suivants ont adopté une approche analogue s'agissant des recours invocables au-dessus et en dessous des seuils : l'Autriche, la Bulgarie, Chypre, l'Estonie, la Hongrie, l'Italie, le Luxembourg, la Lettonie, la Lituanie, 
l'Espagne, la Suède et la Slovénie. Les politiques françaises en matière de recours sont en grande partie similaires pour les marchés supérieurs comme inférieurs aux seuils. Cependant, le choix du tribunal compétent pour juger les affaires est subordonné à la nature juridique (publique ou privée) du pouvoir ou de l'entité adjudicatrice. Aux Pays-Bas, toute infraction aux marchés supérieurs ou inférieurs aux seuils est jugée devant les tribunaux civils, où un délai de suspension de 15 jours peut s'appliquer (dès lors que l'application du droit relatif aux marchés inférieurs aux seuils n'est pas obligatoire). Si l'approche finlandaise en matière de recours est en grande partie identique pour les marchés supérieurs et inférieurs aux seuils, l'inobservation d'un délai de suspension en dessous des seuils limite potentiellement le nombre de plaintes.

Au Royaume-Uni (où il n'existe aucune réglementation pour les marchés de valeur inférieure aux seuils), des procédures informelles peuvent être employées pour dissiper les interrogations concernant la passation de marchés supérieurs comme inférieurs aux seuils. Le service britannique de réaction des fournisseurs (Supplier Feedback Service) et le point de contact unique (Single Point of Contact) en Écosse sont deux procédures informelles qui visent à aider les PME. 


\section{PARTIE II : RÈGLES ET PROCÉDURES COMMUNES NON COUVERTES EN DÉTAIL PAR LES DIRECTIVES EUROPEENNES}

\section{Introduction}

La deuxième partie du présent document s'attache à analyser les politiques et autres pratiques applicables à l'ensemble des marchés, qu'ils soient supérieurs ou inférieurs aux seuils européens. Ces politiques et pratiques s'avèrent toutes aussi importantes que les procédures et les règles présentées en première partie pour établir un cadre procédural exhaustif au niveau national. Ces politiques et autres pratiques qui ne sont pas spécifiquement couvertes dans les directives portent sur l'organisation des procédures de passation, la préparation et le contenu des dossiers d'appel d'offres, les délais de validité des appels d'offres, la soumission et l'ouverture des plis, les garanties d'adjudication et d'exécution, les modalités clarifiant avec détail les offres, ainsi que la suspension et l'annulation des offres.

Si cette étude ne permet pas de déterminer de manière probante le degré de variabilité de ces règles et autres procédures en fonction de la valeur du marché, qu'elle soit supérieure ou inférieure aux seuils européens, certains indices montrent que, dans les secteurs étudiés, les États membres, par souci de simplification, se dotent d'un régime plus souple s'agissant des marchés dont la valeur est inférieure aux seuils fixés par l'UE.

Le fait qu'un État membre soit dépourvu de tout cadre légal régissant un domaine particulier abordé dans la présente étude ne saurait nullement signifier que la pratique opérationnelle de cette procédure ne soit ni mise en œuvre, ni réglementée. C'est le cas, par exemple, du délai de validité de l'offre, que beaucoup d'États membres ont décidé de ne pas réglementer (voir ci-après). Toutefois, si la pratique impose d'indiquer un délai de validité dans l'avis de marché et dans le dossier d'appel d'offres, cette disposition devient de facto obligatoire. Dans le même ordre idée, l'absence de toute réglementation dans le cadre légal portant sur la passation de marchés publics ne signifie pas nécessairement que la question n'est pas réglementée. La question du conflit d'intérêt qui est souvent encadrée par des lois particulières, indépendantes du droit relatif aux marchés publics, en est un parfait exemple.

Afin de mieux comprendre le raisonnement sous-tendant les questions abordées dans cette seconde partie, chaque chapitre débute par une brève note d'information. Ces notes ne sauraient être considérées comme l'expression du point de vue du programme Sigma, mais comme des remarques formulées sur la base des expériences du programme sur la façon dont les pays partenaires élaborent leurs cadres réglementaires pour contrôler la passation des marchés publics, par le passé comme à ce jour.

\subsection{Organisation des procédures d'appel d'offres (question 14)}

\section{Contexte}

Les directives ne contiennent aucune disposition particulière sur l'organisation des procédures d'appel d'offres, à l'exception de l'obligation d'ouvrir les plis après la date butoir dans un souci de confidentialité, et de celle d'employer les systèmes et les équipements généralement disponibles dans le cadre d'offres électroniques. Autrement, la mise en place de ces procédures et autres pratiques, qui varient considérablement, reste une préoccupation exclusivement nationale. Certains États membres prescrivent 
l'ouverture publique des plis ; d'autres préconisent de faire ouvrir les plis par un jury ou une commission. Comme discuté ci-après, le recours à des Commissions d'appels d'offres pour ouvrir et évaluer les offres est une pratique courante dans de nombreux États membres, particulièrement chez les états les plus récents, conformément à leur législation nationale respective. On observe cependant des différences dans les fonctionnements et les mandats conférés aux commissions d'appels d'offres.

\section{Position réglementaire dans les États membres de l'UE}

La présente étude prouve qu'un grand nombre d'États membres contrôlent les pouvoirs adjudicateurs en vertu de la loi sur les marchés publics, soit sur une base ad-hoc pour les offres spécifiques, soit par l'intermédiaire de commissions plus permanentes. La Bulgarie, Chypre, la République tchèque, la Hongrie, la Lettonie, la Lituanie, la Pologne, la Roumanie, et la Slovaquie appartiennent tous à ce groupe d'États membres. Dans le cas de la Pologne, l'instauration de commissions d'appels d'offres est obligatoire pour les marchés dépassant les seuils de l'UE et volontaire en dessous de ces seuils. Les lois sur la passation des marchés publics de ces pays prescrivent généralement des dispositions très détaillées sur les responsabilités, la composition et les méthodes de travail des commissions d'appels d'offres. Il incombera normalement à une commission d'appels d'offres d'ouvrir les plis et d'évaluer les offres.

Un deuxième groupe réunit des pays ayant adopté une approche plus mixte. La France, par exemple, oblige les collectivités territoriales et régionales à instaurer des commissions d'appels d'offres mais, depuis décembre 2008, en exempte les pouvoirs publics. La loi italienne sur la passation des marchés publics exige l'instauration d'une commission d'appels d'offres dès lors que les critères de l'OEPA sont appliqués. Si la loi slovène sur la passation des marchés publics n'impose aucun recours à des commissions d'appels d'offres, dans la pratique, les pouvoirs adjudicateurs les instaurent. C'est également le cas en Estonie, où l'instauration de commissions d'appels d'offres n'est pas imposée par la loi sur la passation des marchés publics, mais reste une pratique courante. En Espagne, les entités adjudicatrices peuvent recourir à des commissions d'appels d'offres (instances collégiales). L'Autriche exige seulement la mise en place d'une commission d'ouverture des plis.

Enfin, un troisième groupe de pays ne prévoit aucune disposition sur l'organisation des procédures d'appels d'offres. L'organisation de la procédure d'appel d'offres est laissée au choix des pouvoirs adjudicateurs. Si cette procédure peut comprendre la formation de commissions ou de groupes de travail, il est rare qu'elle soit plus formalisée. Ces commissions/groupes ont pour vocation exclusive d'apporter leur soutien technique ou commercial aux organisations de tutelle. L'Autriche (voir le paragraphe précédent au sujet de l'exception), le Danemark, la Finlande, les Pays-Bas, l'Irlande, le Luxembourg, la Suède et le RoyaumeUni s'inscrivent dans ce troisième groupe.

Alors que la première partie de cette question s'est intéressée à l'instauration de commissions d'appels d'offres, la seconde partie a tenté d'établir la position adoptée par les pouvoirs adjudicateurs dans leur décision d'adjuger les marchés publics. En d'autres termes, la commission d'appels d'offres est-elle dotée d'un pouvoir décisionnel, ou fournit-elle des recommandations à cette fin à l'attention du pouvoir adjudicateur?

Les règles en vigueur dans les États membres à ce sujet sont difficiles à définir, mais il semble que la majorité des pays qui imposent l'instauration de commissions d'appels d'offres limitent leur pouvoir d'émettre des recommandations sur les décisions d'adjudication des marchés publics, alors que les décisions formelles restent la prérogative d'une personne ou d'un organe agréé au sein du pouvoir adjudicateur. 


\subsection{Sélection et dossier d'appel d'offres (question 15)}

\section{Contexte}

Les directives comprennent des règles détaillées sur la procédure de sélection et d'adjudication ainsi que sur l'élaboration du cahier des charges, mais laissent essentiellement aux États membres le soin de réglementer en détail le contenu de la documentation à fournir pour la procédure de sélection et d'adjudication des appels d'offres. Les directives exigent en guise de conditions de base de faire au moins figurer dans les invitations à présenter une offre, à participer au dialogue compétitif ou à négocier les mentions suivantes :

Une référence à l'avis de marché publié, le délai de réception des offres, l'adresse à laquelle les offres doivent être envoyées, la ou les langues dans lesquelles les offres doivent être rédigées, la référence de tous les documents à joindre, le support des déclarations vérifiables, les informations sur l'aptitude personnelle et les capacités techniques et professionnelles pour la procédure de sélection et la pondération relative des critères d'attribution du marché ou, le cas échéant, l'ordre décroissant d'importance de ces critères.

Certains pays imposent également aux pouvoirs adjudicateurs d'employer un certain modèle de documentation pour ces procédures. Il serait également intéressant de déterminer l'existence de règles, en termes de coûts, sur la délivrance des dossiers d'appel d'offres.

Ces questions se justifient par le rôle stratégique que joue le dossier d'appel d'offres dans la procédure d'appels d'offres. Le dossier doit fournir toutes les informations dont un soumissionnaire potentiel a besoin pour préparer une offre recevable. Bien qu'un dossier puisse varier en contenu et en complexité selon l'importance et la nature du marché, il comprend généralement :

a) l'appel d'offres ;

b) les instructions destinées aux soumissionnaires ;

c) les conditions contractuelles générales et particulières ;

d) le mandat/le cahier des charges.

\section{Position réglementaire dans les États membres de l'UE}

Il est possible de synthétiser certaines caractéristiques communes comme suit :

Si aucun État membre ne prescrit l'utilisation d'un document spécial de sélection/présélection, tous précisent uniquement les informations ainsi que la documentation que les pouvoirs adjudicateurs sont tenus d'exiger de la part des soumissionnaires, conformément aux règles de l'UE, dans les avis et/ou le dossier d'appel d'offres. Il appartient normalement au pouvoir adjudicateur de décider d'émettre ou non un document de sélection spécial, ce qui semble rester dans la pratique assez rare.

- Dans une grande majorité, les États membres incluent dans leurs instruments réglementaires, à divers degrés, le contenu principal du dossier d'appel d'offres en termes d'appels d'offres, d'instructions à l'attention des soumissionnaires, de cahier des charges et de projets de marché.

- $\quad$ Aucun État membre n'impose l'utilisation d'un modèle ou d'un dossier d'appel d'offres normalisé, mais certains pays mettent de tels documents à disposition sous forme de directives et de documentation sur les meilleures pratiques en vigueur.

- La majorité des États membres autorisent, à titre exceptionnel, les pouvoirs adjudicateurs à facturer des frais contre remise d'un dossier d'appel d'offres, de tels frais restant normalement limités au coût réel de reproduction et de fourniture du dossier en question. La transmission électronique tend 
progressivement à s'imposer comme principale méthode de soumission des offres, et à éliminer probablement tout besoin de facturer la remise des dossiers d'appel d'offres.

- $\quad$ Le Danemark, la Finlande, l'Irlande, les Pays-Bas, la Suède et le Royaume-Uni n'appliquent aucune disposition à cet égard ou prévoient des dispositions très limitées dans leurs instruments réglementaires.

- $\quad$ Les États membres n'opèrent aucune distinction entre les règles de sélection et celles relatives aux dossiers d'appel d'offres par rapport à la valeur du marché, que celui-ci soit supérieur ou inférieur aux seuils européens.

\subsection{Règles relatives à l'ouverture des plis (question 16)}

\section{Contexte}

Quelle que soit la procédure imposée dans les réglementations nationales, la session d'ouverture des plis a pour objet de vérifier que les offres sont complètes, que la garantie d'adjudication, le cas échéant, a été fournie, que les documents ont été dûment signés et que les offres sont généralement en règle. La réception et l'ouverture des plis s'effectuent de manière à garantir la régularité des procédures. Les plis sont généralement ouverts par une commission d'appels d'offres ou par un groupe d'au moins deux personnes désignées par le pouvoir adjudicateur. Les informations suivantes sont généralement annoncées lors d'une session d'ouverture des plis : le nom des soumissionnaires, les prix des appels d'offres non encore évalués, la fourniture des garanties d'adjudication requises ainsi que le respect de toute autre formalité ou condition que le pouvoir adjudicateur juge appropriée. Les procès-verbaux des sessions d'ouverture des plis sont préparés et souvent remis aux soumissionnaires participants. La réception et l'ouverture des offres sont considérées comme des étapes importantes dans la procédure de passation de marchés, garantes de l'observation des principes de transparence et d'égalité de traitement.

\section{$\underline{\text { Position réglementaire dans les États membres de l'UE }}$}

Une majorité d'États membres obligent les pouvoirs adjudicateurs (dans le cadre de la loi sur la passation des marchés publics) à ouvrir les plis publiquement et en présence des soumissionnaires et/ou de leurs représentants. L'obligation d'ouvrir les plis en séance publique s'applique à tous les marchés, indépendamment de leur valeur et de leur nature. On observe toutefois certaines différences eu égard au type de procédure, telles que des exceptions à la procédure négociée avec publication préalable ou à la passation d'un marché public en ligne. C'est le cas en Bulgarie, en République tchèque, en Estonie, en Hongrie, en Italie, en Lituanie, au Luxembourg, en Pologne, en Roumanie et en Slovaquie.

Un deuxième groupe d'États membres prévoit des dispositions sur l'ouverture des plis dans leur instrument réglementaire. Ces dispositions peuvent certes prescrire une ouverture publique, assortie dans certains cas de limitations, ou être établies sous forme de conditions à caractère non obligatoire. La loi autrichienne sur la passation des marchés publics fait de l'ouverture publique une règle générale. Dans certains cas justifiables, toutefois, les pouvoirs adjudicateurs peuvent tenir une session à huis clos. À Chypre, l'ouverture publique est envisageable sur décision des pouvoirs adjudicateurs. Au Danemark, les marchés publics de travaux font obligatoirement l'objet d'une ouverture publique des plis, les autres types de marchés étant assujettis à des sessions à huis clos. En Slovénie, les offres sont obligatoirement ouvertes en séance publique pour les marchés supérieurs aux seuils nationaux, les marchés de faible valeur en étant exemptés. L'Espagne relève également, dans une certaine mesure, de ce groupe, puisque les plis doivent être ouverts publiquement dans le cadre d'une procédure ouverte, dans la limite toutefois de règles particulières dès lors que les critères de l'OEPA sont utilisés. 
On distingue enfin un troisième groupe réunissant les pays dans lesquels cette procédure n'est soit pas du tout réglementée, soit non contraignante, soit proscrite. En Finlande, la décision d'ouvrir les plis en séance publique ou à huis clos appartient aux seuls pouvoirs adjudicateurs. La France proscrit l'ouverture publique des plis. En Finlande, le choix est laissé aux pouvoirs adjudicateurs, mais les sessions à huis clos demeurent pratique courante. L'Irlande et le Royaume-Uni ne prévoient aucune disposition à cet égard, mais les sessions d'ouverture à huis clos sont privilégiées.

Il est difficile d'évaluer dans quelle mesure les procédures d'ouverture des plis seront affectées par l'introduction des marchés publics en ligne et par l'attribution d'accords-cadres.

\subsection{Règles relatives aux garanties d'adjudication et d'exécution (question 17)}

\section{Contexte}

Sigma a constaté que l'introduction de dispositions relatives aux garanties d'adjudication et d'exécution dans la loi sur la passation des marchés publics a été et est toujours une pratique courante dans bon nombre de ses pays partenaires. Cette pratique peut généralement se rapporter à la loi modèle de la CNUDCI et au financement des marchés publics par les institutions financières internationales (comme par exemple par la banque mondiale et la BERD). Le choix d'imposer des garanties d'adjudication et d'exécution est fréquemment laissé aux pouvoirs adjudicateurs, mais certains pays possèdent également des règles obligatoires à ce sujet.

Au besoin, le soumissionnaire est prié de fournir une garantie d'adjudication dans le cadre de son offre et d'offrir au pouvoir adjudicateur une protection raisonnable contre les offres irresponsables.

Spécifié dans le dossier d'appels d'offres, le montant d'une telle garantie atteint généralement 1 à $5 \%$ du prix de l'offre. La garantie d'adjudication peut être acquise dans les cas suivants :

a) un soumissionnaire retire son offre dans le délai de validité de l'appel d'offres ;

b) l'adjudicataire manque de conclure le marché, de fournir une garantie d'exécution ou d'accepter de modifier le prix de son offre.

Une garantie d'exécution (normalement 5 à $10 \%$ du prix contractuel) est garante de la bonne exécution du marché et est soumise par l'adjudicataire en guise de condition pour conclure le marché. Le montant de la garantie d'exécution peut être versé à l'acquéreur en compensation de toute perte résultant du manquement de la part du fournisseur d'exécuter ses obligations dans le cadre du marché.

\section{Position réglementaire dans les États membres de l'UE}

La majorité des États membres de l'UE prévoient des dispositions sur les garanties d'adjudication et/ou d'exécution de diverses formes, avec toutefois des différences dans leur application. Ces garanties ne font l'objet d'aucune disposition particulière au Danemark, en Finlande, en France, en Irlande, au Luxembourg, aux Pays-Bas, en Slovénie, en Suède et au Royaume-Uni.

La plupart des pays imposant des garanties d'adjudication et/ou d'exécution laissent aux pouvoirs adjudicateur le choix de leurs recours et le soin de fixer leur montant. Cependant, certains pays en contrôlent l'application aux termes de modalités détaillées. Par exemple, les pouvoirs adjudicateurs polonais sont tenus d'exiger des garanties d'adjudication pour tous les marchés dont la valeur excède les seuils européens et peuvent faire de même pour les marchés de valeur inférieure à ces seuils ; ils doivent également exiger une garantie d'exécution pour les marchés de travaux dont la valeur excède les seuils fixés par l'UE. Dans certains pays (comme par exemple la République tchèque et la Lituanie), les pouvoirs adjudicateurs peuvent requérir des garanties d'adjudication pour les marchés supérieurs aux seuils 
européens mais pas pour les marchés inférieurs à ces seuils. En Lituanie, la demande de garanties d'exécution est obligatoire pour les marchés supérieurs aux seuils fixés par l'UE. De manière forte intéressante, l'Italie impose des garanties pour tous les marchés, à l'exception des marchés de services d'ingénierie.

Comme indiqué précédemment, l'imposition de garanties d'adjudication et d'exécution est chose courante dans une majorité de pays pour les marchés dont la valeur excède ou est inférieure aux seuils européens. Les diverses lois sur la passation des marchés publics rendent leur recours soit obligatoire, soit facultatif. Lorsqu'elles s'appliquent, il semble que ces mêmes lois laissent aux pouvoirs adjudicateurs le choix d'y recourir ou non.

\subsection{Règles relatives à l'annulation des procédures d'appel d'offres (question 18)}

\section{Contexte}

Conformément à la Directive européenne 2004/18 (art 41), en cas d'annulation d'une procédure d'attribution de marché, les pouvoirs adjudicateurs « doivent informer dans les meilleurs délais tous les soumissionnaires de leur décision, ave confirmation écrite si nécessaire, ainsi que des motifs d'une telle annulation. En outre, les pouvoirs adjudicateurs doivent publier au Journal officiel toutes les informations relatives à une annulation de procédure d'attribution dans un avis spécifiquement destiné à fournir des renseignements complémentaires, ainsi que toutes les informations sur la procédure inachevée ou le rectificatif $»$.

En vertu des règles nationales, les pouvoirs adjudicateurs peuvent, avant de conclure un marché, renoncer à l'adjudication ou annuler la procédure d'attribution sans que les candidats ou les soumissionnaires ne soient généralement habilités à prétendre à dédommagement.

L'annulation est permise aux termes des règles nationales dès lors que :

a) la procédure d'appel d'offres s'est avérée infructueuse ; aucune offre ou aucune offre appropriée n'a été reçue ;

b) les données économiques ou techniques liées à l'offre ont fait l'objet de modifications substantielles ;

c) des circonstances exceptionnelles ou un cas de force majeure empêchent l'exécution normale du marché ;

d) toutes les offres techniquement conformes excèdent les ressources financières disponibles ;

e) la procédure a présenté des irrégularités, qui ont plus particulièrement entravé la concurrence loyale.

Avant tout, les règles d'annulation sont souvent prescrites dans l'avis du marché ou dans le dossier d'appel d'offres.

\section{Position réglementaire dans les États membres de l'UE}

La majorité des États membres réglementent l'annulation des procédures d'adjudication de manière plus ou moins détaillée. Les autres pays ne prévoient aucune règle sur l'annulation des procédures d'adjudication, à l'exception des dispositions obligatoires prescrites par les directives. Figurent parmi les États membres dotés de règles détaillées l'Autriche, la Bulgarie, Chypre, la République tchèque, la Hongrie, la Pologne et la Roumanie. Leur législation fournit des informations détaillées sur les motifs d'annulation (obligatoires et facultatives) et prescrit les procédures à suivre. Les motifs d'annulation retenus par ces pays renvoient à la 
liste des pratiques courantes présentées ci-dessus. L'Autriche va même jusqu'à appliquer un délai de suspension de 14 jours pour les marchés supérieurs aux seuils européens et de 7 jours pour les marchés inférieurs à ces seuils avant qu'une décision d'annulation n'entre en vigueur. Le système de révision autrichien permet de faire appel d'une décision d'annulation. En Lituanie, toute décision d'annulation requiert le consentement préalable du Public Procurement Office (bureau des marchés publics) pour les marchés d'une valeur supérieure aux seuils européens.

Un deuxième groupe d'États membres disposent de règles moins détaillées sur l'annulation et se réfèrent parfois à des instruments réglementaires autres que la loi sur la passation des marchés publics. L'Estonie, l'Italie, la Finlande (jurisprudence), le Luxembourg (décret gouvernemental), la Slovénie et l'Espagne font partie de ce groupe. En Slovénie, le pouvoir adjudicateur a le droit d'annuler une procédure d'appel d'offres par commodité sous réserve de pleinement respecter les conditions de notification. Les pouvoirs adjudicateurs espagnols sont, quant à eux, tenus de dédommager les soumissionnaires en cas d'annulation d'une procédure d'adjudication.

Enfin, un troisième groupe de pays ne dispose d'aucune autre règle, hormis celles imposées par les directives européennes. Le Danemark, la France, l'Irlande, la Suède et le Royaume-Uni relèvent de ce groupe.

\subsection{Règles relatives au délai de validité des offres (question 19)}

\section{Contexte}

En règle générale, le délai de validité des offres doit être précisé dans l'avis de marché ainsi que le dossier d'appel d'offres. Ce délai doit également être suffisant pour permettre au pouvoir adjudicateur d'évaluer les offres et de conclure un contrat avec l'adjudicataire. Dans de rares cas, le pouvoir adjudicateur peut demander aux soumissionnaires, avant l'expiration du délai de validité, de prolonger ce délai pour un certain nombre de jours.

Les pouvoirs adjudicateurs doivent ensuite, que le délai de validité de l'appel d'offres soit réglementé ou non dans la législation primaire ou le droit dérivé portant sur la passation de marchés, spécifier le délai de validité des offres dans l'appel à la concurrence, dans l'avis de marché, si le marché fait l'objet d'un avis d'appel d'offres, ou dans les dossiers d'appel d'offres dans le cas d'un appel d'offres direct. Le délai de validité doit dans tous les cas figurer dans le dossier d'appel d'offres.

\section{Position réglementaire dans les États membres de l'UE}

Il est possible d'identifier les modèles suivants :

a) Un premier groupe de pays ont introduit dans leurs législations sur la passation des marchés publics des règles détaillées sur le délai de validité des offres, y compris le nombre de jours applicable selon les circonstances. L'Autriche, Chypre, le Luxembourg, la Pologne et l'Espagne en font partie. En Autriche, le délai de validité dans les cas normaux est limité à 5 mois maximum, et peut aller dans de rares cas jusqu'à 7 mois. Si aucun délai de validité n'est spécifié, un délai d'1 mois s'appliquera. À Chypre, le délai maximal est de 6 mois. Au Luxembourg, le délai normal est de 2 mois et peut être prolongé jusqu'à 4 mois. Toute prolongation nécessaire de ce délai au-delà de 4 mois requiert l'accord des soumissionnaires. La Pologne fixe un délai de validité de 30 jours pour les marchés de valeur inférieure aux seuils européens. Au-delà de ces seuils, le délai normal est de 60 jours maximum. Pour les marchés à forte valeur, la période maximale est fixée à 90 jours. En Espagne, le critère d'attribution utilisé détermine la durée de validité des offres. L'attribution doit avoir lieu dans un délai de 15 jours si le critère du prix le 
plus bas est utilisé et dans un délai de 30 jours (à moins qu'un autre délai n'ait été mentionné dans l'appel d'offres) si le critère de l'OEPA est utilisé.

b) Un deuxième groupe de pays réglementent également le délai de validité des offres, mais contrairement au premier groupe, les pouvoirs adjudicateurs peuvent déterminer la durée de ce délai. Ce groupe, le plus important, inclut la Bulgarie, la République tchèque, l'Estonie, la France, la Hongrie, l'Italie, la Lituanie, la Roumanie et la Slovaquie. La Roumanie dispose également de directives préconisant un délai de validité de 90 à 120 jours. En l'absence de toute indication dans l'appel d'offres, l'Italie observe un délai de 180 jours.

c) Enfin, un troisième groupe de pays ne dispose d'aucune règle, ou alors de règles très limitées, sur le délai de validité des offres. Ce groupe englobe le Danemark, la Finlande, l'Irlande, les PaysBas, la Slovénie, la Suède et le Royaume-Uni.

\subsection{Utilisation du système de la double enveloppe (question 20)}

\section{Contexte}

Le système de la double enveloppe, en vertu duquel les propositions techniques et financières sont soumises sous plis distincts devant être ouverts à différentes dates, permet de différencier la qualité du prix, dans l'optique d'éviter toute évaluation technique biaisée à l'issue de laquelle toute considération de prix pourrait être préjudiciable à la qualité. Dans le cadre de cette étude, Sigma est parvenu à la conclusion qu'un certain nombre de ses pays partenaires ont adopté des lois sur la passation des marchés publics prescrivant le recours au système de la double enveloppe. Cette pratique est couramment utilisée la passation de marchés de services de consultance dans les projets financés par les institutions financières internationales (comme par exemple la banque mondiale et la BERD).

\section{Position réglementaire dans les États membres de l'UE}

La procédure de la double enveloppe n'est que très rarement réglementée dans les États membres. Les pouvoirs adjudicateurs peuvent y avoir recours, sur libre choix de leur part.

Les seuls pays à avoir adopté des règles sur la procédure de la double enveloppe sont la Bulgarie, l'Italie et la Lituanie. La Bulgarie a rendu obligatoire le système de la double enveloppe pour tous les marchés conclus à l'issue d'une procédure d'adjudication. Si le critère de l'OEPA est retenu, l'offre financière n'est ouverte qu'à l'issue de l'évaluation des autres critères. La jurisprudence italienne rend obligatoire le système de la double enveloppe, alors que le droit dérivé prescrit le recours à cette procédure pour les marchés de travaux. En Lituanie, la procédure de la double enveloppe est obligatoire pour les marchés dont la valeur excède les seuils européens et lorsque le critère de l'OEPA est retenu.

\subsection{Règles relatives au conflit d'intérêt (question 21)}

\section{Contexte}

Les conflits d'intérêt peuvent revêtir diverses formes et survenir à différents niveaux dans la procédure de passation des marchés publics. La question reste complexe à traiter dans le cadre de la passation de marchés. Toute politique relative au conflit d'intérêt vise à garantir des conditions de concurrence équitables et justes à tous les participants. Certains cas de conflit d'intérêt sont aisément identifiables. D'autres sont moins évidents et reposent souvent sur le principe de l'avantage compétitif déloyal, dont la preuve est plus difficile à fournir. 
Par conséquent, les règles de passation des marchés chercheront également à limiter les cas de conflit potentiel en incluant des dispositions sur l'impartialité et la confidentialité. Figurent au nombre de dispositions utilisées pour prévenir tout conflit d'intérêt :

- l'interdiction de participer à des procédures d'adjudication de marchés dans lesquelles les responsables des appels d'offres sont liés de quelque manière que ce soit (lien familial, social ou financier) avec l'un des soumissionnaires ;

- $\quad$ l'obligation pour ces responsables de se déclarer eux-mêmes inéligibles ;

- $\quad$ l'obligation pour ces responsables de signer des déclarations à cet effet ;

- l'interdiction de participer à un quelconque appel d'offres pour tout fonctionnaire de l'État (par ex., en tant qu'expert).

Les soumissionnaires, quant à eux, peuvent être essentiellement confrontés à des conflits d'intérêt résultant de relations et de connexions susceptibles de leur procurer, dans certains cas, un avantage déloyal. Dès lors que les conditions de concurrence équitables sont avant tout respectées, ni les directives, ni le code sur les marchés publics ne permettent d'exclure des entreprises pour des motifs d'ordre général. Toute exclusion doit être motivée, au cas par cas, sur la preuve avérée d'un conflit d'intérêt. Cette position a été également adoptée par la CJE dans l'affaire Fabricom.

Il convient également de noter que la question du conflit d'intérêt concerne non seulement la législation relative à la passation de marchés publics, mais également les réglementations promulguées dans d'autres actes, y compris les lois spécifiques sur les conflits d'intérêt. Dans certaines lois sur la passation des marchés publics, le conflit d'intérêt ne fait l'objet d'aucune clause intégrale mais y est inséré, par exemple, en vertu de l'organisation des procédures d'appel d'offres (adhésion aux commissions d'appels d'offres).

\section{Position réglementaire dans les États membres de l'UE}

Beaucoup d'États membres disposent de règles sur le conflit d'intérêt dans leur cadre réglementaire sur la passation de marchés publics. Afin de garantir l'impartialité des organisations, une majorité de pays établissent des règles pour traiter les situations susceptibles de se produire au sein des pouvoirs adjudicateurs, notamment la composition d'une commission d'appel d'offres et les relations entre ses membres. Un plus petit nombre d'États membres préfèrent réglementer les modalités de soumission des offres.

Figurent au nombre des pays dotés de règles détaillées sur le conflit d'intérêt la Bulgarie, Chypre, l'Estonie, la Hongrie, l'Italie, la Pologne, la Roumanie, la Slovaquie, la Slovénie et l'Espagne.

Le cadre réglementaire relative à la passation des marchés publics des autres États membres ne prévoit aucune règle sur le conflit d'intérêt, qui peut néanmoins faire l'objet d'autres lois.

\subsection{Règles particulières applicables à l'attribution de marchés de services de conseil et autres services intellectuels (question 22)}

\section{Contexte}

En apportant son concours dans la préparation de la législation sur la passation des marchés publics, Sigma a identifié une question commune concernant la façon d'organiser l'attribution des marchés de services de conseil ou de services intellectuels. La nécessité d'inclure des dispositions particulières à ce sujet a été avancée en raison de la nature spécifique de ces marchés, dans lesquels la qualité prime fréquemment sur le prix et les autres considérations se rapportant aux coûts. Lorsque la réglementation sur la passation des marchés publics prévoit des procédures particulières pour les services de conseil, le système de la double 
enveloppe (cf. 2.7) est généralement utilisé. De telles procédures particulières les services de consultance peuvent se rapporter à la loi type de la CNUDCI ainsi qu'aux règles de passation des marchés des institutions financières internationales (IFI), telles que la banque mondiale et la BERD.

Les directives européennes proposent à la fois des procédures (restreintes ou, une fois justifiées, négociées) et une méthodologie d'évaluation (l'OEPA) qui, une fois combinées, permettent aux pouvoirs adjudicateurs d'élaborer une procédure de passation d'adjudication limitant le recours à de telles procédures particulières.

\section{Position réglementaire dans les États membres de l'UE}

La manière dont les États membres abordent cette question tend à confirmer l'ébauche de conclusion susmentionnée. Une très grande majorité de pays n'incluent aucune disposition spécifique sur l'attribution de services intellectuels et laissent aux pouvoirs adjudicateurs le soin d'élaborer des procédures sur la base des directives européennes telles que transposées dans le droit national.

Seules les réglementations sur la passation des marchés publics de trois pays, l'Autriche, l'Italie et l'Espagne, comprennent des règles particulières sur l'attribution des services architecturaux et des prestations d'ingénierie.

\subsection{Changements de réglementation planifiés (question 23)}

Au moment de rédiger la présente publication, seuls quelques États membres semblent avoir prévu de modifier leur cadre réglementaire en sus des amendements requis à des fins d'harmonisation avec le droit européen, comme la transposition de la nouvelle directive amendée portant sur les recours.

L'Autriche, la Finlande, la Lituanie et la Slovénie ont prévu d'amender leur cadre juridique en dehors du champ d'application des directives. La Suède introduira dans son droit en 2010 un seuil autorisant la passation directe de marchés. Les Pays-Bas ont l'intention d'assouplir leur loi sur la passation des marchés en faveur des PME en y inscrivant explicitement les principes de non-discrimination et de proportionnalité. Elle inclura des orientations sur le principe de proportionnalité assorties d'exemples pratiques.

En raison de la crise économique, l'Autriche introduira, à titre de mesure temporaire jusqu'à fin 2010, la possibilité d'attribuer directement les marchés de biens et de services à hauteur de 100000 EUR, et les marchés de travaux à hauteur d'1 million EUR. La Finlande prévoit d'introduire un système de bons de services pour les services II B, groupe 25 , avec recours à des procédures concurrentielles particulières. La Lituanie introduira de nouvelles exigences en matière de publication pour son portail Web central, couvrant les prévisions annuelles de passation de marchés, les rapports d'adjudication, et les dossiers d'appels d'offres. Enfin, la Slovénie introduira de nouvelles règles de publication pour les avis de marché de biens et de services (entre 10000 et 40000 EUR) et pour les marchés de travaux (entre 20000 et 80 000 EUR). 
ANNEXE 1 : TABLEAU RÉCAPITULATIF

PARTIE I : RÈGLES ET AUTRES PROCÉDURES APPLICABLES EN-DESSOUS DES SEUILS FIXÉS PAR L'UE

\begin{tabular}{|c|c|c|c|c|c|c|}
\hline État membre & $\begin{array}{l}\text { Instrument } \\
\text { réglementaire }\end{array}$ & Seuils & Méthodes & $\begin{array}{c}\text { Règles relatives } \\
\text { aux appels } \\
\text { d'offres }\end{array}$ & Délais & $\begin{array}{c}\text { Autres règles } \\
\text { (Critères de sélection, } \\
\text { critères d'attribution, } \\
\text { cahier des charges et } \\
\text { recours) }\end{array}$ \\
\hline Autriche & $\begin{array}{l}\text { BVergG } 2006 \\
\text { couvre le secteur } \\
\text { classique et les } \\
\text { secteurs particuliers } \\
\text { pour les marchés } \\
\text { supérieurs et } \\
\text { inférieurs aux seuils } \\
\text { européens. }\end{array}$ & $\begin{array}{l}\text { < } 40000 \text { EUR : } \\
\text { acquisition directe } \\
\text { pour le secteur } \\
\text { classique. } \\
\text { < } 60000 \text { EUR : } \\
\text { acquisition directe } \\
\text { dans les secteurs } \\
\text { particuliers. } \\
\text { < } 120000 \text { EUR } \\
\text { (travaux) et } 80000 \\
\text { EUR (fournitures } \\
\text { et services) : appel } \\
\text { d'offres restreint } \\
\text { sans publication } \\
\text { (secteurs } \\
\text { classiques). }\end{array}$ & $\begin{array}{l}\text { 1. Procédures } \\
\text { européennes. } \\
\text { 2. Procédures } \\
\text { négociées avec ou } \\
\text { sans publication } \\
\text { préalable, dans la } \\
\text { limite de certains } \\
\text { seuils nationaux. } \\
\text { 3. Appel d'offres } \\
\text { restreint sans } \\
\text { publication } \\
\text { préalable. } \\
\text { 4. Acquisition } \\
\text { directe. }\end{array}$ & $\begin{array}{l}\text { Publication } \\
\text { requise pour } \\
\text { toute procédure } \\
\text { négociée jusqu'à } \\
350 \text { 000 EUR } \\
\text { (marché de } \\
\text { travaux) et dans } \\
\text { la limite des } \\
\text { seuils européens } \\
\text { (marché de } \\
\text { fournitures et } \\
\text { services). }\end{array}$ & $\begin{array}{l}\text { Présentation des } \\
\text { demandes de } \\
\text { participation : } 14 \\
\text { jours. } \\
\text { Soumission des } \\
\text { offres : } 22 \text { jours. }\end{array}$ & $\begin{array}{l}\text { Les règles } \\
\text { applicables sont } \\
\text { essentiellement } \\
\text { identiques, que les } \\
\text { marchés soient } \\
\text { inférieurs ou } \\
\text { supérieurs aux seuils } \\
\text { européens. }\end{array}$ \\
\hline
\end{tabular}




\begin{tabular}{|c|c|c|c|c|c|c|}
\hline État membre & $\begin{array}{l}\text { Instrument } \\
\text { réglementaire }\end{array}$ & Seuils & Méthodes & $\begin{array}{l}\text { Règles relatives } \\
\text { aux appels } \\
\text { d'offres }\end{array}$ & Délais & $\begin{array}{c}\text { Autres règles } \\
\text { (Critères de sélection, } \\
\text { critères d'attribution, } \\
\text { cahier des charges et } \\
\text { recours) }\end{array}$ \\
\hline Bulgarie & $\begin{array}{l}\text { La loi sur les } \\
\text { marchés } \\
\text { publics couvre } \\
\text { le secteur } \\
\text { classique et les } \\
\text { secteurs } \\
\text { particuliers (loi } \\
\text { sur la passation } \\
\text { des marchés } \\
\text { publics). } \\
\text { Décret } \\
\text { gouvernemental } \\
\text { sur la passation } \\
\text { des marchés de } \\
\text { faible valeur } \\
\text { (OASPC). } \\
\text { Ordonnance sur } \\
\text { l'attribution de } \\
\text { marchés à } \\
\text { usage } \\
\text { particulier } \\
\text { (défense et } \\
\text { sécurité). }\end{array}$ & $\begin{array}{l}\text { Les seuils sont les mêmes } \\
\text { pour le secteur classique } \\
\text { et pour les secteurs } \\
\text { particuliers. } \\
\text { La loi sur la passation des } \\
\text { marchés publics observe } \\
\text { les procédures } \\
\text { européennes. } \\
>1075000 \text { EUR } \\
\text { (travaux). } \\
>90000 \text { EUR } \\
\text { (fournitures). } \\
>50000 \text { EUR (services). } \\
\text { L'OASPC s'applique } \\
\text { selon des procédures } \\
\text { simplifiées en dessous } \\
\text { des seuils visés ci-dessus } \\
\text { et } \\
>100000 \text { EUR (travaux). } \\
>25000 \text { EUR } \\
\text { (fournitures et services). }\end{array}$ & $\begin{array}{l}\text { Procédure } \\
\text { européenne au- } \\
\text { dessus de la } \\
\text { première } \\
\text { fourchette } \\
\text { Concours ouvert } \\
\text { et la procédure } \\
\text { négociée avec } \\
\text { appel d'offres } \\
\text { (justification } \\
\text { requise) pour la } \\
\text { deuxième } \\
\text { fourchette. } \\
\text { Rassemblement } \\
\text { des offres, sous } \\
\text { réserve de réunir } \\
\text { au moins trois } \\
\text { offres dans la } \\
\text { troisième } \\
\text { fourchette. } \\
\text { Acquisition } \\
\text { directe en dessous } \\
\text { de la dernière }\end{array}$ & $\begin{array}{l}\text { Publication dans } \\
\text { la gazette de } \\
\text { l'État et dans le } \\
\text { registre national } \\
\text { des marchés } \\
\text { publics au-dessus } \\
\text { de la première } \\
\text { fourchette des } \\
\text { seuils nationaux. } \\
\text { Registre des } \\
\text { marchés publics } \\
\text { en dessous de la } \\
\text { première } \\
\text { fourchette de } \\
\text { seuils. } \\
\text { L'appel d'offres } \\
\text { lancé en vertu du } \\
\text { rassemblement } \\
\text { d'offres peut être } \\
\text { publié sur } \\
\text { différents } \\
\text { supports. }\end{array}$ & $\begin{array}{l}\text { Les délais pour } \\
\text { les marchés } \\
\text { supérieurs à la } \\
\text { première } \\
\text { fourchette suivent } \\
\text { les règles } \\
\text { européennes, et } \\
\text { sont fixés à } 33 \\
\text { jours pour les } \\
\text { marchés } \\
\text { inférieurs, voire à } \\
\mathbf{2 2} \text { jours dans } \\
\text { certains cas. Les } \\
\text { délais sont encore } \\
\text { plus réduits avec } \\
\text { l'utilisation de } \\
\text { moyens } \\
\text { électroniques. }\end{array}$ & $\begin{array}{l}\text { Les règles } \\
\text { applicables sont } \\
\text { fondamentalement } \\
\text { identiques, que les } \\
\text { marchés soient } \\
\text { inférieurs ou } \\
\text { supérieurs aux seuils } \\
\text { européens. }\end{array}$ \\
\hline
\end{tabular}




\begin{tabular}{|l|l|l|l|l|l|l|}
\hline État membre & $\begin{array}{c}\text { Instrument } \\
\text { réglementaire }\end{array}$ & Seuils & Méthodes & $\begin{array}{c}\text { Règles relatives } \\
\text { aux appels } \\
\text { d'offres }\end{array}$ & $\begin{array}{c}\text { Autres règles } \\
\text { (Critères de sélection, } \\
\text { critères d'attribution, } \\
\text { cahier des charges et } \\
\text { recours) }\end{array}$ \\
\hline & & $\begin{array}{l}<22000 \text { EUR (travaux). } \\
<7500 \text { EUR (fournitures } \\
\text { et services). }\end{array}$ & fourchette. & & \\
\hline
\end{tabular}

\begin{tabular}{|c|c|c|c|c|c|c|}
\hline État membre & $\begin{array}{c}\text { Instrument } \\
\text { réglementaire }\end{array}$ & Seuils & Méthodes & $\begin{array}{c}\text { Règles relatives } \\
\text { aux appels d'offres }\end{array}$ & Délais & $\begin{array}{c}\text { Autres règles } \\
\text { (Critères de sélection, } \\
\text { critères d'attribution, } \\
\text { cahier des charges et } \\
\text { recours) }\end{array}$ \\
\hline Chypre & $\begin{array}{l}\text { La loi sur les marchés } \\
\text { publics L.12 (i) de } \\
2006 \text { passés dans le } \\
\text { secteur classique } \\
\text { couvre les marchés } \\
\text { dont la valeur est } \\
\text { supérieure comme } \\
\text { inférieure aux seuils } \\
\text { fixés par l'UE. } \\
\text { La loi sur les marchés } \\
\text { publics } 11 \text { (i) de } 2006 \\
\text { passés dans les secteurs } \\
\text { spéciaux ne couvre pas } \\
\text { les marchés dont la } \\
\text { valeur est inférieure }\end{array}$ & $\begin{array}{l}>85000 \text { EUR : } \\
\text { application des } \\
\text { procédures } \\
\text { européennes. } \\
<85000 \text { EUR : } \\
\text { application de } \\
\text { procédures } \\
\text { simplifiées. } \\
<1700 \text { EUR: } \\
\text { attribution directe. }\end{array}$ & $\begin{array}{l}\text { En sus des } \\
\text { procédures } \\
\text { européennes, des } \\
\text { procédures } \\
\text { concurrentielles } \\
\text { simplifiées } \\
\text { s'appliquent en } \\
\text { dessous du seuil } \\
\text { national de } 85 \\
\text { 000 EUR. }\end{array}$ & $\begin{array}{l}\text { Au-dessus du seuil } \\
\text { national, } \\
\text { publication dans la } \\
\text { gazette officielle. }\end{array}$ & $\begin{array}{l}\text { Les délais de } \\
\text { soumission des offres } \\
\text { sont de } \mathbf{1 4} \text { jours et de } \\
\mathbf{1 0} \text { jours dans le cadre } \\
\text { de procédures } \\
\text { ouvertes, et de } \mathbf{1 4} \\
\text { jours dans le cadre de } \\
\text { procédures restreintes } \\
\text { pour les marchés } \\
\text { inférieurs aux seuils } \\
\text { fixés par l'UE. } \\
\text { Les mêmes délais } \\
\text { s'appliquent pour la } \\
\text { procédure simplifiée }\end{array}$ & $\begin{array}{l}\text { Les règles applicables } \\
\text { sont fondamentalement } \\
\text { identiques, que les } \\
\text { marchés soient } \\
\text { inférieurs ou supérieurs } \\
\text { aux seuils européens. }\end{array}$ \\
\hline
\end{tabular}




\begin{tabular}{|c|c|c|c|c|c|c|}
\hline État membre & $\begin{array}{l}\text { Instrument } \\
\text { réglementaire }\end{array}$ & Seuils & Méthodes & $\begin{array}{c}\text { Règles relatives } \\
\text { aux appels d'offres }\end{array}$ & Délais & $\begin{array}{c}\text { Autres règles } \\
\text { (Critères de sélection, } \\
\text { critères d'attribution, } \\
\text { cahier des charges et } \\
\text { recours) }\end{array}$ \\
\hline & $\begin{array}{l}\text { aux seuils européens. } \\
\text { Les réglementations } \\
\text { internes applicables à } \\
\text { ces marchés sont } \\
\text { semblables aux règles } \\
\text { imposées en vertu de la } \\
\text { loi sur la passation des } \\
\text { marchés publics. }\end{array}$ & & & & (10 et 14 jours). & \\
\hline $\begin{array}{l}\text { République } \\
\text { tchèque }\end{array}$ & $\begin{array}{l}\text { La loi sur les marchés } \\
\text { publics }(137 / 2006) \\
\text { passés dans le secteur } \\
\text { classique et les secteurs } \\
\text { spéciaux s'applique aux } \\
\text { marchés de valeur } \\
\text { inférieure aux seuils } \\
\text { européens pour le } \\
\text { secteur classique mais } \\
\text { pas pour les secteurs } \\
\text { spéciaux. Les marchés } \\
\text { concernant les secteurs } \\
\text { spéciaux ne sont pas } \\
\text { réglementés en dessous } \\
\text { des seuils européens. }\end{array}$ & $\begin{array}{l}>70000 \text { EUR pour } \\
\text { les procédures } \\
\text { européennes } \\
\text { applicables aux } \\
\text { fournitures et aux } \\
\text { services, sous réserve } \\
\text { d'une certaine } \\
\text { simplification } \\
>210000 \text { EUR pour } \\
\text { les travaux : } \\
\text { Procédures } \\
\text { européennes sous } \\
\text { réserve d'une certaine } \\
\text { simplification. } \\
\text { En dessous de ces } \\
\text { seuils nationaux, les } \\
\text { principes du Traité } \\
\text { s'appliquent. }\end{array}$ & $\begin{array}{l}\text { Au-dessus des } \\
\text { seuils nationaux, } \\
\text { application de } \\
\text { procédures } \\
\text { identiques à } \\
\text { celles visées } \\
\text { dans les } \\
\text { directives de } \\
\text { l'UE ou d'une } \\
\text { procédure } \\
\text { concurrentielle } \\
\text { simplifiée avec } \\
\text { publication } \\
\text { préalable (sous } \\
\text { réserve d'au } \\
\text { moins cinq } \\
\text { soumissionnaires } \\
\text { participants). }\end{array}$ & $\begin{array}{l}\text { Publication sur le } \\
\text { portail Web central } \\
\text { pour les offres } \\
\text { supérieures aux } \\
\text { seuils nationaux. } \\
\text { Modèle d'avis de } \\
\text { marché identique à } \\
\text { celui utilisé pour les } \\
\text { marchés supérieurs } \\
\text { aux seuils } \\
\text { européens. } \\
\text { Publication des avis } \\
\text { de marchés sur son } \\
\text { propre site Web en } \\
\text { vertu de la } \\
\text { procédure } \\
\text { simplifiée. }\end{array}$ & $\begin{array}{l}\text { Les délais de } \\
\text { soumission des offres } \\
\text { dans le cadre de la } \\
\text { procédure ouverte sont } \\
\text { de } \mathbf{2 2} \text { jours et de } \mathbf{1 5} \\
\text { jours dans le cadre de } \\
\text { procédures restreintes } \\
\text { et simplifiées. Dans ce } \\
\text { dernier cas, le délai } \\
\text { peut être ramené à } \mathbf{7} \\
\text { jours en cas } \\
\text { d'urgence. Le délai de } \\
\text { participation des } \\
\text { demandes de } \\
\text { participation est de } \mathbf{1 5} \\
\text { jours ou de } \mathbf{1 0} \text { jours } \\
\text { en cas d'urgence. }\end{array}$ & $\begin{array}{l}\text { Les règles applicables } \\
\text { sont fondamentalement } \\
\text { identiques, que les } \\
\text { marchés soient } \\
\text { inférieurs ou supérieurs } \\
\text { aux seuils européens. }\end{array}$ \\
\hline
\end{tabular}




\begin{tabular}{|c|c|c|c|c|c|c|}
\hline $\begin{array}{l}\text { État } \\
\text { membre }\end{array}$ & $\begin{array}{l}\text { Instrument } \\
\text { réglementaire }\end{array}$ & Seuils & Méthodes & $\begin{array}{l}\text { Règles relatives aux } \\
\text { appels d'offres }\end{array}$ & Délais & $\begin{array}{c}\text { Autres règles } \\
\text { (Critères de sélection, } \\
\text { critères d'attribution, } \\
\text { cahier des charges et } \\
\text { recours) }\end{array}$ \\
\hline Danemark & $\begin{array}{l}\text { La passation des } \\
\text { marchés de travaux } \\
\text { inférieurs aux seuils } \\
\text { européens et supérieurs } \\
\text { au seuil national dans le } \\
\text { secteur classique est } \\
\text { régie par la Loi } \\
338 / 2005 \text { sur les } \\
\text { procédures } \\
\text { d'adjudication des } \\
\text { marchés publics de } \\
\text { travaux. L'attribution } \\
\text { des marchés de } \\
\text { fournitures et de } \\
\text { services supérieurs au } \\
\text { seuil national dans le } \\
\text { secteur classique est } \\
\text { régie par la Loi } \\
1410 / 2007 \text { sur les } \\
\text { procédures } \\
\text { d'adjudication des } \\
\text { marchés de travaux } \\
\text { publics. }\end{array}$ & $\begin{array}{l}67000 \text { EUR } \\
\text { pour les biens, } \\
\text { les travaux et } \\
\text { les services } \\
\text { (pouvoirs } \\
\text { publics). } \\
40000 \text { EUR } \\
\text { pour les } \\
\text { travaux. }\end{array}$ & $\begin{array}{l}\text { Tout type de } \\
\text { procédure } \\
\text { applicable, mais } \\
\text { les pouvoirs } \\
\text { publics centraux } \\
\text { sont tenus de faire } \\
\text { un appel d'offres } \\
\text { et de publier un } \\
\text { avis de marché } \\
\text { dès lors que les } \\
\text { marchés excèdent } \\
\text { les seuils } \\
\text { nationaux. }\end{array}$ & $\begin{array}{l}\text { Publication d'un avis } \\
\text { de marché. Tous les } \\
\text { supports peuvent } \\
\text { être utilisés. }\end{array}$ & $\begin{array}{l}\text { En cas de } \\
\text { procédure } \\
\text { restreinte, le délai } \\
\text { de présentation } \\
\text { des demandes de } \\
\text { participation est } \\
\text { de } \mathbf{1 5} \text { jours. }\end{array}$ & $\begin{array}{l}\text { Directives } \\
\text { européennes, mais } \\
\text { décision laissée aux } \\
\text { pouvoirs } \\
\text { adjudicateurs. } \\
\text { Les marchés d'une } \\
\text { valeur inférieure aux } \\
\text { seuils européens sont } \\
\text { sujets à des } \\
\text { procédures de } \\
\text { plaintes identiques à } \\
\text { celles qui } \\
\text { s'appliquent aux } \\
\text { marchés excédant les } \\
\text { seuils européens. }\end{array}$ \\
\hline
\end{tabular}




\begin{tabular}{|l|l|l|l|l|l|l|}
\hline $\begin{array}{l}\text { État } \\
\text { membre }\end{array}$ & \multicolumn{1}{c|}{$\begin{array}{c}\text { Instrument } \\
\text { réglementaire }\end{array}$} & Seuils & Méthodes & $\begin{array}{c}\text { Règles relatives aux } \\
\text { appels d'offres }\end{array}$ & $\begin{array}{c}\text { Autres règles } \\
\text { (Critères de sélection, } \\
\text { critères d'attribution, } \\
\text { cahier des charges et } \\
\text { recours) }\end{array}$ \\
\hline & $\begin{array}{l}\text { L'attribution des } \\
\text { marchés est également } \\
\text { régie par des arrétés } \\
\text { gouvernementaux et } \\
\text { ministériels. } \\
\text { Les secteurs spéciaux en } \\
\text { sont exclus. } \\
\text { Les principes du Traité } \\
\text { s'appliquent. }\end{array}$ & & & \\
\hline
\end{tabular}

\begin{tabular}{|c|c|c|c|c|c|c|}
\hline État membre & $\begin{array}{l}\text { Instrument } \\
\text { réglementaire }\end{array}$ & Seuils & Méthodes & $\begin{array}{c}\text { Règles } \\
\text { relatives aux } \\
\text { appels } \\
\text { d'offres }\end{array}$ & Délais & $\begin{array}{c}\text { Autres règles } \\
\text { (Critères de sélection, } \\
\text { critères d'attribution, } \\
\text { cahier des charges et } \\
\text { recours) }\end{array}$ \\
\hline Estonie & $\begin{array}{l}\text { La loi sur les marchés } \\
\text { publics de } 2007 \\
\text { s'applique aux marchés } \\
\text { d'une valeur inférieure } \\
\text { aux seuils européens } \\
\text { dans le secteur } \\
\text { classique et les }\end{array}$ & $\begin{array}{l}40000 \text { EUR pour les } \\
\text { biens et les services et } \\
250000 \text { EUR pour les } \\
\text { marchés de travaux } \\
\text { dans les secteurs } \\
\text { classiques, plus des } \\
\text { seuils spéciaux dans }\end{array}$ & $\begin{array}{l}\text { Toutes les } \\
\text { procédures } \\
\text { (ouvertes, } \\
\text { restreintes et } \\
\text { négociées) } \\
\text { peuvent } \\
\text { s'appliquer }\end{array}$ & $\begin{array}{l}\text { Publication } \\
\text { des avis sur le } \\
\text { portail Web } \\
\text { central de } \\
\text { publication à } \\
\text { la fois pour } \\
\text { les entités du }\end{array}$ & $\begin{array}{l}\text { Le délai dans le } \\
\text { cadre d'une } \\
\text { procédure ouverte } \\
\text { est de } \mathbf{2 2} \text { jours } \\
\text { pour les marchés } \\
\text { de travaux et de } \\
\mathbf{1 5} \text { jours pour les }\end{array}$ & $\begin{array}{l}\text { Les règles } \\
\text { applicables sont } \\
\text { fondamentalement } \\
\text { identiques, que les } \\
\text { marchés soient } \\
\text { inférieurs ou } \\
\text { supérieurs aux seuils }\end{array}$ \\
\hline
\end{tabular}




\begin{tabular}{|c|c|c|c|c|c|c|}
\hline État membre & $\begin{array}{l}\text { Instrument } \\
\text { réglementaire }\end{array}$ & Seuils & Méthodes & $\begin{array}{c}\text { Règles } \\
\text { relatives aux } \\
\text { appels } \\
\text { d'offres }\end{array}$ & Délais & $\begin{array}{c}\text { Autres règles } \\
\text { (Critères de sélection, } \\
\text { critères d'attribution, } \\
\text { cahier des charges et } \\
\text { recours) }\end{array}$ \\
\hline & $\begin{array}{l}\text { secteurs spéciaux. } \\
\text { Application des } \\
\text { principes du Traité de } \\
\text { l'UE. }\end{array}$ & $\begin{array}{l}\text { des cas spécifiques. } \\
\text { Application des } \\
\text { principes du Traité en } \\
\text { dessous de ces seuils. } \\
\text { Aucun seuil pour les } \\
\text { secteurs spéciaux. } \\
\text { Obligation de garantir } \\
\text { une concurrence } \\
\text { efficace. }\end{array}$ & $\begin{array}{l}\text { librement sous } \\
\text { réserve d'une } \\
\text { publication } \\
\text { préalable. }\end{array}$ & $\begin{array}{l}\text { secteur } \\
\text { classique et } \\
\text { pour celles } \\
\text { des secteurs } \\
\text { spéciaux. }\end{array}$ & $\begin{array}{l}\text { marchés de biens } \\
\text { et de services. Le } \\
\text { délai de } \\
\text { présentation des } \\
\text { demandes de } \\
\text { participation est } \\
\text { de } 7 \text { jours. }\end{array}$ & européens. \\
\hline Finlande & $\begin{array}{l}\text { La loi }(348 / 2007) \text { sur } \\
\text { la passation des } \\
\text { marchés publics et la } \\
\text { loi (349/2007) } \\
\text { régissant les secteurs } \\
\text { spéciaux s'appliquent } \\
\text { aux marchés inférieurs } \\
\text { comme supérieurs aux } \\
\text { seuils européens. } \\
\text { Cependant, } \\
\text { l'attribution des } \\
\text { marchés dans les } \\
\text { secteurs spéciaux n'est } \\
\text { pas réglementée. Un } \\
\text { décret définit les }\end{array}$ & $\begin{array}{l}\text { La loi sur la passation } \\
\text { des marchés publics ne } \\
\text { s'applique pas : } \\
<15000 \text { EUR pour les } \\
\text { biens et les services et } \\
<100000 \text { EUR pour } \\
\text { les travaux. } \\
\text { La procédure négociée } \\
\text { avec publication } \\
\text { préalable peut être } \\
\text { utilisée pour les } \\
\text { marchés de biens et de } \\
\text { services < } 50000 \text { EUR } \\
\text { et pour les marchés de }\end{array}$ & $\begin{array}{l}\text { Au-dessus des } \\
\text { seuils nationaux, } \\
\text { les procédures } \\
\text { européennes } \\
\text { sont simplifiées. } \\
\text { Possibilité de } \\
\text { passer } \\
\text { directement les } \\
\text { marchés sous } \\
\text { réserve de } \\
\text { justifications } \\
\text { semblables à } \\
\text { celles visées } \\
\text { dans les } \\
\text { directives. }\end{array}$ & $\begin{array}{l}\text { Publication } \\
\text { sur le portail } \\
\text { Web central et } \\
\text { sur d'autres } \\
\text { supports. }\end{array}$ & $\begin{array}{l}\text { Aucun délai } \\
\text { stipulé ; prévoir } \\
\text { un délai } \\
\text { raisonnable pour } \\
\text { la soumission des } \\
\text { offres. }\end{array}$ & $\begin{array}{l}\text { Les règles } \\
\text { applicables sont } \\
\text { fondamentalement } \\
\text { identiques, que les } \\
\text { marchés soient } \\
\text { supérieurs ou } \\
\text { inférieurs aux seuils } \\
\text { européens. Aucun } \\
\text { délai de suspension, } \\
\text { néanmoins. }\end{array}$ \\
\hline
\end{tabular}




\begin{tabular}{|l|l|l|l|l|l|l|}
\hline État membre & \multicolumn{1}{|c|}{$\begin{array}{c}\text { Instrument } \\
\text { réglementaire }\end{array}$} & Seuils & Méthodes & $\begin{array}{c}\text { Règles } \\
\text { relatives aux } \\
\text { appels } \\
\text { d'offres }\end{array}$ & $\begin{array}{c}\text { Autres règles } \\
\text { (Critères de sélection, } \\
\text { critères d'attribution, } \\
\text { cahier des charges et } \\
\text { recours) }\end{array}$ \\
\hline & $\begin{array}{l}\text { conditions de } \\
\text { publication requises } \\
\text { dans les deux secteurs. } \\
\text { Application des } \\
\text { obligations du Traité. }\end{array}$ & $\begin{array}{l}\text { travaux }<500000 \\
\text { EUR. }\end{array}$ & & & & \\
\hline
\end{tabular}

\begin{tabular}{|c|c|c|c|c|c|c|}
\hline État membre & $\begin{array}{l}\text { Instrument } \\
\text { réglementaire }\end{array}$ & Seuils & Méthodes & $\begin{array}{l}\text { Règles relatives } \\
\text { aux appels } \\
\text { d'offres }\end{array}$ & Délais & $\begin{array}{c}\text { Autres règles } \\
\text { (Critères de sélection, } \\
\text { critères d'attribution, } \\
\text { cahier des charges et } \\
\text { recours) }\end{array}$ \\
\hline France : & $\begin{array}{l}\text { Code des marchés } \\
\text { publics, } \\
\text { Ordonnance } \\
2005 / 649 \text {, } \\
\text { Décret 2005/1742, } \\
\text { Décret 2005/1308. }\end{array}$ & $\begin{array}{l}<90000 \text { EUR : les } \\
\text { modalités de } \\
\text { publication des avis } \\
\text { sont déterminées } \\
\text { par le responsable } \\
\text { des appels d'offres } \\
\text { en fonction de } \\
\text { l'objet du marché, } \\
\text { de son montant et } \\
\text { du niveau de } \\
\text { concurrence. } \\
\text { Entre } 90000 \text { EUR }\end{array}$ & $\begin{array}{l}\text { < } 4000 \text { EUR : } \\
\text { aucune obligation. } \\
\text { < seuils européens } \\
\text { : le responsable des } \\
\text { appels d'offres } \\
\text { définit librement la } \\
\text { procédure selon les } \\
\text { nécessités, le } \\
\text { nombre ou } \\
\text { l'implantation } \\
\text { géographique des }\end{array}$ & $\begin{array}{l}\text { < seuils } \\
\text { européens : } \\
\text { formulaires } \\
\text { normalisés } \\
\text { spécifiques, } \\
\text { modalités de } \\
\text { publication } \\
\text { déterminées par } \\
\text { le pouvoir } \\
\text { adjudicateur (voir } \\
\text { les « seuils »). }\end{array}$ & $\begin{array}{l}<\text { seuils } \\
\text { européens : délais } \\
\text { établis par le } \\
\text { pouvoir } \\
\text { adjudicateur (voir } \\
\text { les « seuils »). } \\
\text { > seuils } \\
\text { européens : délais } \\
\text { établis dans les } \\
\text { directives. }\end{array}$ & $\begin{array}{l}\text { < seuils européens : } \\
\text { modalités } \\
\text { déterminées par le } \\
\text { pouvoir adjudicateur } \\
\text { (voir les « seuils ») } \\
\text { conformément aux } \\
\text { principes du Traité de } \\
\text { l'UE. } \\
\text { > seuils européens : } \\
\text { règles établies dans } \\
\text { les directives. }\end{array}$ \\
\hline
\end{tabular}




\begin{tabular}{|c|c|c|c|c|c|c|}
\hline État membre & $\begin{array}{l}\text { Instrument } \\
\text { réglementaire }\end{array}$ & Seuils & Méthodes & $\begin{array}{l}\text { Règles relatives } \\
\text { aux appels } \\
\text { d'offres }\end{array}$ & Délais & $\begin{array}{c}\text { Autres règles } \\
\text { (Critères de sélection, } \\
\text { critères d'attribution, } \\
\text { cahier des charges et } \\
\text { recours) }\end{array}$ \\
\hline & & $\begin{array}{l}\text { et les seuils } \\
\text { européens : avis à } \\
\text { publier dans le } \\
\text { bulletin officiel ou } \\
\text { dans un journal } \\
\text { habilité à publier } \\
\text { des avis légaux. } \\
\text { > seuils fixés par } \\
\text { l'UE : avis à publier } \\
\text { dans le bulletin } \\
\text { officiel et dans } \\
\text { l'OJEU. }\end{array}$ & $\begin{array}{l}\text { opérateurs } \\
\text { économiques } \\
\text { susceptibles d'y } \\
\text { répondre. } \\
\text { > seuils européens } \\
\text { : procédures } \\
\text { définies par les } \\
\text { directives. }\end{array}$ & $\begin{array}{l}\text { > seuils } \\
\text { européens : } \\
\text { modalités établies } \\
\text { dans les } \\
\text { directives. }\end{array}$ & & \\
\hline
\end{tabular}

\begin{tabular}{|l|l|l|l|l|l|l|}
\hline État membre & \multicolumn{1}{|l|}{$\begin{array}{c}\text { Instrument } \\
\text { réglementaire }\end{array}$} & \multicolumn{1}{|c|}{ Seuils } & Méthodes & $\begin{array}{c}\text { Règles } \\
\text { relatives aux } \\
\text { appels d'offres }\end{array}$ & $\begin{array}{c}\text { Autres règles } \\
\text { (Critères de } \\
\text { sélection, critères } \\
\text { d'attribution, cahier } \\
\text { des charges et } \\
\text { recours) }\end{array}$ \\
\hline Hongrie & $\begin{array}{l}\text { Loi CXXIX sur les } \\
\text { marchés publics. }\end{array}$ & $\begin{array}{l}\text { Secteurs classiques } \\
<26700 \text { EUR } \\
\text { (fournitures et services) et }\end{array}$ & $\begin{array}{l}\text { < seuils } \\
\text { européens : } \\
\text { procédure } \\
\text { ouverte ou }\end{array}$ & $\begin{array}{l}\text { Obligation de } \\
\text { publier un avis } \\
\text { dans le bulletin } \\
\text { des marchés }\end{array}$ & $\begin{array}{l}\text { < seuils européens : } \\
\text { délai de soumission } \\
\text { des offres déterminé } \\
\text { par le pouvoir }\end{array}$ & $\begin{array}{l}\text { Les règles } \\
\text { applicables sont } \\
\text { fondamentalement } \\
\text { identiques, que les }\end{array}$ \\
\hline
\end{tabular}




\begin{tabular}{|c|c|c|c|c|c|c|}
\hline État membre & $\begin{array}{l}\text { Instrument } \\
\text { réglementaire }\end{array}$ & Seuils & Méthodes & $\begin{array}{c}\text { Règles } \\
\text { relatives aux } \\
\text { appels d'offres }\end{array}$ & Délais & $\begin{array}{l}\text { Autres règles } \\
\text { (Critères de } \\
\text { sélection, critères } \\
\text { d'attribution, cahier } \\
\text { des charges et } \\
\text { recours) }\end{array}$ \\
\hline & & $\begin{array}{l}<50000 \text { EUR (travaux) : } \\
\text { aucune obligation. } \\
\text { Secteurs spéciaux. } \\
<166700 \text { EUR } \\
\text { (fournitures et services) et } \\
<333300 \text { EUR (travaux) } \\
\text { : aucune obligation. }\end{array}$ & $\begin{array}{l}\text { restreinte } \\
\text { mais les } \\
\text { pouvoirs } \\
\text { adjudicateurs } \\
\text { sont } \\
\text { autorisés à } \\
\text { négocier si } \\
\text { ils en } \\
\text { manifestent } \\
\text { l'intention } \\
\text { dans l'appel } \\
\text { d'offres. }\end{array}$ & $\begin{array}{l}\text { publics. } \\
\text { Formulaires } \\
\text { normalisés pour } \\
\text { les marchés < } \\
\text { seuils } \\
\text { européens, très } \\
\text { semblables aux } \\
\text { formulaires } \\
\text { standards de } \\
\text { l'UE. }\end{array}$ & $\begin{array}{l}\text { adjudicateur, sous } \\
\text { réserve d'un délai } \\
\text { minimal de } \mathbf{2 5} \\
\text { jours. Ce délai peut } \\
\text { être réduit de } \mathbf{5} \\
\text { jours à condition } \\
\text { que les } \\
\text { spécifications de } \\
\text { l'offre et les } \\
\text { informations } \\
\text { additionnelles } \\
\text { soient fournies } \\
\text { électroniquement. }\end{array}$ & $\begin{array}{l}\text { marchés soient } \\
\text { inférieurs ou } \\
\text { supérieurs aux } \\
\text { seuils européens. }\end{array}$ \\
\hline Irlande & $\begin{array}{l}\text { Aucune } \\
\text { réglementation en } \\
\text { dessous des seuils } \\
\text { fixés par l'UE. Les } \\
\text { directives nationales } \\
\text { sur la passation des } \\
\text { marchés publics sont } \\
\text { disponibles sur le site } \\
\text { Web national des } \\
\text { marchés publics }\end{array}$ & $\begin{array}{l}\text { Les directives nationales } \\
\text { établissent comme règle } \\
\text { générale de publier les } \\
\text { marchés > 50 000 EUR } \\
\text { sur le site Web national } \\
\text { des marchés publics. Les } \\
\text { procédures internes de } \\
\text { nombreux pouvoirs } \\
\text { adjudicateurs exigent de } \\
\text { publier les marchés dont }\end{array}$ & $\begin{array}{l}\text { Aucune } \\
\text { méthode } \\
\text { prescrite } \\
\text { mais les } \\
\text { procédures } \\
\text { ouvertes sont } \\
\text { les plus } \\
\text { utilisées pour } \\
\text { les marchés } \\
\text { dont la }\end{array}$ & Non précisé & Non précisé & Non précisé \\
\hline
\end{tabular}




\begin{tabular}{|l|l|l|l|l|l|}
\hline État membre & $\begin{array}{c}\text { Instrument } \\
\text { réglementaire }\end{array}$ & Seuils & Méthodes & $\begin{array}{c}\text { Autres règles } \\
\text { Règles } \\
\text { relatives aux } \\
\text { appels d'offres }\end{array}$ & $\begin{array}{c}\text { Célection, critères de } \\
\text { Délais } \\
\text { d'attribution, cahier } \\
\text { des charges et } \\
\text { recours) }\end{array}$ \\
\hline & www.etenders.gov.ie & $\begin{array}{l}\text { la valeur est inférieure à } \\
\text { ce seuil. }\end{array}$ & $\begin{array}{l}\text { valeur est } \\
\text { inférieure } \\
\text { aux seuils } \\
\text { européens. }\end{array}$ & \\
\hline
\end{tabular}

\begin{tabular}{|c|c|c|c|c|c|c|}
\hline $\begin{array}{l}\text { État } \\
\text { membre }\end{array}$ & $\begin{array}{l}\text { Instrument } \\
\text { réglementaire }\end{array}$ & Seuils & Méthodes & $\begin{array}{c}\text { Règles relatives } \\
\text { aux appels d'offres }\end{array}$ & Délais & $\begin{array}{c}\text { Autres règles } \\
\text { (Critères de sélection, } \\
\text { critères d'attribution, } \\
\text { cahier des charges et } \\
\text { recours) }\end{array}$ \\
\hline Italie & $\begin{array}{l}\text { Décret } \\
\text { présidentiel } \\
163 / 2006 \\
\text { («code des } \\
\text { marchés } \\
\text { publics »). }\end{array}$ & $\begin{array}{l}\text { Secteurs classiques } \\
<20000 \text { EUR } \\
\text { (fournitures et services) } \\
\text { et } \\
<40000 \text { EUR (travaux) } \\
\text { : achat direct autorisé. } \\
<500000 \text { EUR } \\
\text { (travaux) : procédure } \\
\text { négociée sans préavis } \\
\text { autorisée. } \\
<750000 \text { EUR }\end{array}$ & $\begin{array}{l}\text { Procédures } \\
\text { analogues pour } \\
\text { les marchés } \\
\text { supérieurs et } \\
\text { inférieurs aux } \\
\text { seuils européens. }\end{array}$ & $\begin{array}{l}\text { Publication } \\
\text { obligatoire des avis } \\
\text { de marchés et des } \\
\text { avis d'attribution des } \\
\text { marchés. } \\
\text { Marchés de travaux } \\
>500000 \text { EUR et } \\
\text { marchés de } \\
\text { fournitures et de } \\
\text { services : } \\
\text { publication dans le }\end{array}$ & $\begin{array}{l}\text { Procédure ouverte : } \\
\mathbf{2 6} \text { jours (travaux) } \\
\mathbf{1 5} \text { jours } \\
\text { (fournitures/services). } \\
\text { Procédure restreinte } \\
\text { ou négociée avec avis } \\
: \\
\mathbf{1 5}+\mathbf{2 0} \text { jours } \\
\text { (travaux) }\end{array}$ & $\begin{array}{l}\text { Les règles } \\
\text { applicables sont } \\
\text { fondamentalement } \\
\text { identiques, que les } \\
\text { marchés soient } \\
\text { supérieurs ou } \\
\text { inférieurs aux seuils } \\
\text { européens. }\end{array}$ \\
\hline
\end{tabular}




\begin{tabular}{|c|c|c|c|c|c|c|}
\hline $\begin{array}{l}\text { État } \\
\text { membre }\end{array}$ & $\begin{array}{l}\text { Instrument } \\
\text { réglementaire }\end{array}$ & Seuils & Méthodes & $\begin{array}{c}\text { Règles relatives } \\
\text { aux appels d'offres }\end{array}$ & Délais & $\begin{array}{c}\text { Autres règles } \\
\text { (Critères de sélection, } \\
\text { critères d'attribution, } \\
\text { cahier des charges et } \\
\text { recours) }\end{array}$ \\
\hline & & $\begin{array}{l}\text { (travaux) : procédure } \\
\text { restreinte simplifiée } \\
\text { autorisée. } \\
\text { Secteurs spéciaux. } \\
\text { Entités adjudicatrices qui } \\
\text { sont également des } \\
\text { pouvoirs adjudicateurs : } \\
\text { seuils semblables. } \\
\text { Sociétés publiques, de } \\
\text { même qu'entités privées } \\
\text { agissant sur la base de } \\
\text { droits spéciaux ou } \\
\text { exclusifs : règles } \\
\text { stipulées dans leurs } \\
\text { réglementations. }\end{array}$ & & $\begin{array}{l}\text { Journal officiel } \\
\text { national et sur le site } \\
\text { Web de l'autorité de } \\
\text { surveillance des } \\
\text { marchés publics. } \\
\text { Marchés de travaux } \\
\text { < } 500000 \text { EUR: } \\
\text { publication sur le } \\
\text { panneau d'affichage } \\
\text { du pouvoir } \\
\text { adjudicateur. }\end{array}$ & $\begin{array}{l}\mathbf{7 + 1 0} \text { jours } \\
\text { (fournitures/services). }\end{array}$ & \\
\hline
\end{tabular}




\begin{tabular}{|c|c|c|c|c|c|c|}
\hline $\begin{array}{l}\text { État } \\
\text { membre }\end{array}$ & $\begin{array}{l}\text { Instrument } \\
\text { réglementaire }\end{array}$ & Seuils & Méthodes & $\begin{array}{c}\text { Règles relatives } \\
\text { aux appels } \\
\text { d'offres }\end{array}$ & Délais & $\begin{array}{c}\text { Autres règles } \\
\text { (Critères de sélection, } \\
\text { critères d'attribution, } \\
\text { cahier des charges et } \\
\text { recours) }\end{array}$ \\
\hline Lettonie & $\begin{array}{l}\text { Loi sur les marchés publics } \\
\text { passés dans le secteur } \\
\text { classique, dont la valeur } \\
\text { est supérieure ou inférieure } \\
\text { aux seuils européens, et loi } \\
\text { sur la passation de marchés } \\
\text { dans les secteurs spéciaux, } \\
\text { cette dernière ne } \\
\text { s'appliquant pas en dessous } \\
\text { des seuils fixés par l'UE. }\end{array}$ & $\begin{array}{l}\text { Achat Direct : } \\
<4200 \text { EUR pour } \\
\text { les biens et les } \\
\text { services et } 14000 \\
\text { EUR pour les } \\
\text { travaux. } \\
\text { Procédure } \\
\text { simplifiée : } \\
\text { < } 30000 \text { EUR } \\
\text { pour les biens et } \\
\text { les services et < } \\
170 \text { 000 EUR pour } \\
\text { les travaux. }\end{array}$ & $\begin{array}{l}\text { Au-dessus des seuils } \\
\text { nationaux, les } \\
\text { procédures } \\
\text { européennes sont } \\
\text { simplifiées. } \\
\text { En dessous des seuils } \\
\text { nationaux, } \\
\text { application des } \\
\text { procédures } \\
\text { nationales } \\
\text { simplifiées }\end{array}$ & $\begin{array}{l}\text { Règles de } \\
\text { publication } \\
\text { similaires aux } \\
\text { conditions } \\
\text { applicables au- } \\
\text { dessus des seuils } \\
\text { européens pour les } \\
\text { marchés dont la } \\
\text { valeur excède les } \\
\text { seuils nationaux. } \\
\text { Publication sur le } \\
\text { portail Web } \\
\text { central. } \\
\text { En dessous des } \\
\text { seuils nationaux, } \\
\text { les règles d'appel } \\
\text { d'offres simplifiées } \\
\text { s'appliquent. }\end{array}$ & $\begin{array}{l}\text { Pour la procédure } \\
\text { ouverte, le délai est } \\
\text { de } \mathbf{3 0} \text { jours, et de } \\
\mathbf{2 5} \text { jours pour la } \\
\text { présentation des } \\
\text { demandes de } \\
\text { participation en cas } \\
\text { de procédure } \\
\text { restreinte et } \\
\text { négociée. Le délai } \\
\text { de soumission des } \\
\text { offres est de } \mathbf{2 5} \\
\text { jours. } \\
\text { En dessous du seuil } \\
\text { national, le délai est } \\
\text { de } \mathbf{1 5} \text { jours. }\end{array}$ & $\begin{array}{l}\text { Les règles applicables } \\
\text { sont fondamentalement } \\
\text { identiques, que les } \\
\text { marchés soient } \\
\text { inférieurs ou supérieurs } \\
\text { aux seuils européens. } \\
\text { Aucune plainte ne peut } \\
\text { être déposée en dessous } \\
\text { des seuils nationaux ( } 30 \\
\text { 000 EUR et } 170000 \\
\text { EUR), ni pour les } \\
\text { marchés d'une valeur } \\
\text { inférieure aux seuils } \\
\text { européens dans les } \\
\text { secteurs spéciaux. }\end{array}$ \\
\hline Lituanie & $\begin{array}{l}\text { La loi sur les marchés } \\
\text { publics réglemente la } \\
\text { passation des marchés } \\
\text { publics dans le secteur } \\
\text { classique, dans les secteurs } \\
\text { spéciaux, ainsi que la } \\
\text { passation de marchés } \\
\text { inférieurs aux seuils fixés } \\
\text { par l'UE. }\end{array}$ & $\begin{array}{l}30000 \text { EUR pour } \\
\text { les biens et les } \\
\text { services et } 145 \\
000 \text { EUR pour les } \\
\text { marchés de } \\
\text { travaux. } \\
3000 \text { EUR pour } \\
\text { les achats directs. }\end{array}$ & $\begin{array}{l}\text { Au-dessus des seuils } \\
\text { nationaux, il est } \\
\text { recommandé } \\
\text { d'appliquer les } \\
\text { procédures } \\
\text { européennes } \\
\text { simplifiées. } \\
\text { Les entités œuvrant } \\
\text { dans les secteurs }\end{array}$ & $\begin{array}{l}\text { Publication des } \\
\text { avis de marchés sur } \\
\text { le portail Web } \\
\text { central ainsi que } \\
\text { dans la gazette } \\
\text { officielle. } \\
\text { Publication d'avis } \\
\text { de marchés } \\
\text { également dans les }\end{array}$ & $\begin{array}{l}\text { Sept jours à } \\
\text { compter de la } \\
\text { publication de l'avis } \\
\text { d'un marché. }\end{array}$ & $\begin{array}{l}\text { Les règles applicables } \\
\text { sont fondamentalement } \\
\text { identiques, que les } \\
\text { marchés soient } \\
\text { inférieurs ou supérieurs } \\
\text { aux seuils européens. }\end{array}$ \\
\hline
\end{tabular}




\begin{tabular}{|l|l|l|l|l|l|}
\hline $\begin{array}{l}\text { État } \\
\text { membre }\end{array}$ & \multicolumn{1}{|c|}{$\begin{array}{c}\text { Instrument } \\
\text { réglementaire }\end{array}$} & Seuils & Méthodes & $\begin{array}{c}\text { Autres règles } \\
\text { aux appels } \\
\text { d'offres }\end{array}$ & $\begin{array}{c}\text { Dèlais } \\
\text { (Critères de sélection, } \\
\text { critères d'attribution, } \\
\text { cahier des charges et } \\
\text { recours) }\end{array}$ \\
\hline $\begin{array}{l}\text { Les entités adjudicatrices } \\
\text { dans les secteurs spéciaux, } \\
\text { de même que les pouvoirs } \\
\text { adjudicateurs dans le } \\
\text { secteur classique, doivent } \\
\text { préparer leurs propres } \\
\text { réglementations à publier } \\
\text { sur le portail Web central. }\end{array}$ & $\begin{array}{l}\text { spéciaux et dans le } \\
\text { secteur classique } \\
\text { établiront leurs } \\
\text { propres procédures } \\
\text { par réglementation } \\
\text { interne. }\end{array}$ & secteurs spéciaux. & \\
\hline
\end{tabular}

\begin{tabular}{|l|l|l|l|l|l|l|}
\hline État membre & $\begin{array}{l}\text { Instrument } \\
\text { réglementaire }\end{array}$ & \multicolumn{1}{|c|}{ Seuils } & Méthodes & $\begin{array}{l}\text { Règles relatives } \\
\text { aux appels } \\
\text { d'offres }\end{array}$ & $\begin{array}{c}\text { Autres règles } \\
\text { (Critères de } \\
\text { sélection, critères } \\
\text { d'attribution, cahier } \\
\text { des charges et } \\
\text { recours }\end{array}$ \\
\hline Luxembourg & $\begin{array}{l}\text { Loi sur les } \\
\text { marchés } \\
\text { publics de } \\
2009 .\end{array}$ & $\begin{array}{l}\text { procédure négociée } \\
\text { sans publication. } \\
<100 \text { 000 EUR : } \\
\text { procédure négociée } \\
\text { sans publication, sous } \\
\text { réserve d'inviter au } \\
\text { moins 3 opérateurs }\end{array}$ & $\begin{array}{l}\text { Procédure négociée sans } \\
\text { publication (se reporter } \\
\text { au seuil). } \\
\text { Procédure négociée (se } \\
\text { reporter au seuil) sans } \\
\text { publication, sous réserve } \\
\text { d'inviter au moins 3 } \\
\text { opérateurs économiques }\end{array}$ & $\begin{array}{l}\text { Publication d'un } \\
\text { avis obligatoire } \\
\text { sur le portail } \\
\text { Internet hébergé } \\
\text { par le ministère } \\
\text { des travaux } \\
\text { publics ainsi que } \\
\text { dans deux } \\
\text { journaux }\end{array}$ & $\begin{array}{l}\text { Procédure } \\
\text { ouverte : 42 } \\
\text { jours. Ce délai } \\
\text { peut être ramené } \\
\text { à 21 jours. }\end{array}$ & $\begin{array}{l}\text { Les règles } \\
\text { applicables sont } \\
\text { fondamentalement } \\
\text { identiques, que les } \\
\text { marchés soient } \\
\text { inférieurs ou } \\
\text { supérieurs aux } \\
\text { seuils européens. }\end{array}$ \\
\hline
\end{tabular}




\begin{tabular}{|c|c|c|c|c|c|c|}
\hline État membre & $\begin{array}{l}\text { Instrument } \\
\text { réglementaire }\end{array}$ & Seuils & Méthodes & $\begin{array}{c}\text { Règles relatives } \\
\text { aux appels } \\
\text { d'offres }\end{array}$ & Délais & $\begin{array}{l}\text { Autres règles } \\
\text { (Critères de } \\
\text { sélection, critères } \\
\text { d'attribution, cahier } \\
\text { des charges et } \\
\text { recours) }\end{array}$ \\
\hline & & $\begin{array}{l}\text { économiques à } \\
\text { soumettre leur offre. } \\
>100000 \text { EUR : } \\
\text { procédure ouverte } \\
\text { obligatoire, à moins } \\
\text { que la procédure } \\
\text { négociée avec ou sans } \\
\text { publication ne soit } \\
\text { autorisée par les } \\
\text { directives } \\
\text { européennes. } \\
>800000 \text { EUR : } \\
\text { procédure restreinte } \\
\text { également autorisée } \\
\text { pour les marchés de } \\
\text { travaux. }\end{array}$ & $\begin{array}{l}\text { à soumettre leur offre. } \\
\text { Procédure ouverte (se } \\
\text { reporter au seuil) } \\
\text { obligatoire, à moins que } \\
\text { la procédure négociée } \\
\text { avec ou sans publication } \\
\text { ne soit autorisée par les } \\
\text { directives européennes. } \\
\text { Procédure restreinte (se } \\
\text { reporter au seuil) } \\
\text { également autorisée } \\
\text { pour les marchés de } \\
\text { travaux. }\end{array}$ & $\begin{array}{l}\text { nationaux pour les } \\
\text { marchés } \\
>100000 \text { EUR. } \\
\text { Modèles d'avis } \\
\text { normalisés } \\
\text { simplifiés en } \\
\text { dessous des seuils } \\
\text { fixés par l'UE. } \\
\text { Formulaires } \\
\text { normalisés } \\
\text { différents pour les } \\
\text { secteurs spéciaux. }\end{array}$ & & \\
\hline
\end{tabular}

\begin{tabular}{|l|l|l|l|l|l|c|}
\hline $\begin{array}{l}\text { État } \\
\text { membre }\end{array}$ & $\begin{array}{c}\text { Instrument } \\
\text { réglementaire }\end{array}$ & Seuils & Méthodes & $\begin{array}{c}\text { Règles relatives } \\
\text { aux appels } \\
\text { d'offres }\end{array}$ & Délais & $\begin{array}{c}\text { Autres règles } \\
\text { (Critères de sélection, critères } \\
\text { d'attribution, cahier des charges } \\
\text { et recours) }\end{array}$ \\
\hline
\end{tabular}




\begin{tabular}{|c|c|c|c|c|c|c|}
\hline $\begin{array}{l}\text { État } \\
\text { membre }\end{array}$ & $\begin{array}{l}\text { Instrument } \\
\text { réglementaire }\end{array}$ & Seuils & Méthodes & $\begin{array}{l}\text { Règles relatives } \\
\text { aux appels } \\
\text { d'offres }\end{array}$ & Délais & $\begin{array}{c}\text { Autres règles } \\
\text { (Critères de sélection, critères } \\
\text { d'attribution, cahier des charges } \\
\text { et recours) }\end{array}$ \\
\hline Pays-Bas & $\begin{array}{l}\text { Une loi-cadre pour } \\
\text { mettre en œuvre les } \\
\text { directives } \\
\text { européennes. } \\
\text { Aucun instrument } \\
\text { réglementaire pour les } \\
\text { marchés inférieurs aux } \\
\text { seuils européens. } \\
\text { Des recommandations } \\
\text { (non obligatoires) sont } \\
\text { émises pour le secteur } \\
\text { classique (uniquement } \\
\text { pour les marchés de } \\
\text { travaux) comme pour } \\
\text { les secteurs spéciaux. } \\
\text { L'application d'une } \\
\text { nouvelle loi sur les } \\
\text { marchés publics est } \\
\text { prévue pour } 2011 .\end{array}$ & Non précisé & $\begin{array}{l}\text { Appel d'offres } \\
\text { restreint avec } \\
\text { invitation } \\
\text { directes à } \\
\text { soumettre. } \\
\text { Les entités } \\
\text { adjudicatrices } \\
\text { déterminent } \\
\text { leur propre } \\
\text { politique et } \\
\text { règles pour les } \\
\text { marchés } \\
\text { concurrentiels. }\end{array}$ & Non précisé & Non précisé & Non précisé \\
\hline Pologne & $\begin{array}{l}\text { La loi sur les marchés } \\
\text { publics (du } 29 \text { janvier } \\
\text { 2004) réglemente la } \\
\text { passation des marchés } \\
\text { dans le secteur } \\
\text { classique et les } \\
\text { secteurs spéciaux, dont } \\
\text { la valeur est supérieure }\end{array}$ & $\begin{array}{l}\text { La loi sur la } \\
\text { passation des } \\
\text { marchés } \\
\text { publics ne } \\
\text { s'applique } \\
\text { pas aux } \\
\text { marchés } \\
\text { d'une valeur }\end{array}$ & $\begin{array}{l}\text { En dessous } \\
\text { des seuils } \\
\text { fixés par l'UE, } \\
\text { application } \\
\text { des procédures } \\
\text { européennes } \\
\text { simplifiées. }\end{array}$ & $\begin{array}{l}\text { Les avis de marchés } \\
\text { et d'attribution } \\
\text { doivent etre publiés } \\
\text { sur le portail Web } \\
\text { central des marchés } \\
\text { publics. }\end{array}$ & $\begin{array}{l}\text { Demandes de } \\
\text { participation : } \mathbf{7} \text { jours. } \\
\text { Procédure ouverte }: \mathbf{2 0} \\
\text { jours pour les travaux et } \\
\mathbf{7} \text { jours pour les biens et } \\
\text { les services. } \\
\text { Procédure restreinte : } \mathbf{1 4} \\
\text { jours pour les travaux et }\end{array}$ & $\begin{array}{l}\text { Les règles applicables sont } \\
\text { fondamentalement identiques, } \\
\text { que les marchés soient } \\
\text { inférieurs ou supérieurs aux } \\
\text { seuils européens. } \\
\text { La loi sur la passation des } \\
\text { marchés publics autorise de } \\
\text { porter plainte pour tous types de }\end{array}$ \\
\hline
\end{tabular}




\begin{tabular}{|c|c|c|c|c|c|c|}
\hline $\begin{array}{l}\text { État } \\
\text { membre }\end{array}$ & $\begin{array}{l}\text { Instrument } \\
\text { réglementaire }\end{array}$ & Seuils & Méthodes & $\begin{array}{c}\text { Règles relatives } \\
\text { aux appels } \\
\text { d'offres }\end{array}$ & Délais & $\begin{array}{c}\text { Autres règles } \\
\text { (Critères de sélection, critères } \\
\text { d'attribution, cahier des charges } \\
\text { et recours) }\end{array}$ \\
\hline & $\begin{array}{l}\text { aux seuils européens, } \\
\text { ainsi que la passation } \\
\text { des marchés d'une } \\
\text { valeur inférieure aux } \\
\text { seuils européens dans } \\
\text { le secteur classique. }\end{array}$ & $\begin{array}{l}\text { inférieure à } \\
14000 \text { EUR. }\end{array}$ & & & $\begin{array}{l}\mathbf{7} \text { jours pour les biens et } \\
\text { les services. } \\
\text { Dialogue compétitif et } \\
\text { procédure négociée } \mathbf{1 0} \\
\text { jours. }\end{array}$ & $\begin{array}{l}\text { marchés (à l'exception des } \\
\text { marchés inférieurs aux seuils } \\
\text { européens dans les secteurs } \\
\text { spéciaux). Cependant, l'appel } \\
\text { des décisions d'adjudication en } \\
\text { dessous des seuils européens } \\
\text { sera limité selon la nature de la } \\
\text { plainte. }\end{array}$ \\
\hline
\end{tabular}

\begin{tabular}{|c|c|c|c|c|c|c|}
\hline État membre & $\begin{array}{c}\text { Instrument } \\
\text { réglementaire }\end{array}$ & Seuils & Méthodes & $\begin{array}{c}\text { Règles relatives } \\
\text { aux appels } \\
\text { d'offres }\end{array}$ & Délais & $\begin{array}{c}\text { Autres règles } \\
\text { (Critères de sélection, } \\
\text { critères d'attribution, } \\
\text { cahier des charges et } \\
\text { recours) }\end{array}$ \\
\hline Roumanie & $\begin{array}{l}\text { Loi sur les marchés } \\
\text { publics promulguée } \\
\text { par GEO 34/2006, et } \\
\text { loi 337/2006 et droit } \\
\text { dérivé par GD } \\
\text { 925/2006. } \\
\text { La loi sur la passation } \\
\text { des marchés publics } \\
\text { couvre les marchés du } \\
\text { secteur classique et des } \\
\text { secteurs spéciaux }\end{array}$ & $\begin{array}{l}<15000 \text { EUR : } \\
\text { achat direct. } \\
<100000 \text { EUR pour } \\
\text { les marchés de } \\
\text { fournitures et de } \\
\text { services et } 750000 \\
\text { EUR pour les } \\
\text { marchés de travaux : } \\
\text { procédures } \\
\text { simplifiées. } \\
\text { Au-dessus des seuils }\end{array}$ & $\begin{array}{l}\text { Procédure simplifiée } \\
\text { avec demande de } \\
\text { participation en } \\
\text { dessous des seuils } \\
\text { nationaux. } \\
\text { Dans les autres cas, } \\
\text { application } \\
\text { essentiellement des } \\
\text { procédures visées } \\
\text { dans les directives } \\
\text { européennes. }\end{array}$ & $\begin{array}{l}\text { Publication des } \\
\text { avis de marchés et } \\
\text { des avis } \\
\text { d'attribution sur le } \\
\text { portail Web central } \\
\text { (ESPP) dans une } \\
\text { version simplifiée. } \\
\text { Au-dessus des } \\
\text { seuils nationaux, } \\
\text { les formulaires } \\
\text { d'avis de l'UE sont }\end{array}$ & $\begin{array}{l}\text { Le délai de } \\
\text { soumission des } \\
\text { offres en vertu de la } \\
\text { procédure } \\
\text { simplifiée est de } \mathbf{1 0} \\
\text { jours et peut être } \\
\text { réduit à } \mathbf{6} \text { jours en } \\
\text { cas de soumission } \\
\text { électronique. } \\
\text { Au-dessus des } \\
\text { seuils nationaux, le }\end{array}$ & $\begin{array}{l}\text { Les règles applicables } \\
\text { sont fondamentalement } \\
\text { identiques, que les } \\
\text { marchés soient } \\
\text { inférieurs ou supérieurs } \\
\text { aux seuils européens. } \\
\text { Le délai de suspension } \\
\text { est de } \mathbf{6} \text { jours en } \\
\text { dessous des seuils } \\
\text { européens et de } \mathbf{1 1} \\
\text { jours au-dessus de ces }\end{array}$ \\
\hline
\end{tabular}




\begin{tabular}{|c|c|c|c|c|c|c|}
\hline État membre & $\begin{array}{l}\text { Instrument } \\
\text { réglementaire }\end{array}$ & Seuils & Méthodes & $\begin{array}{l}\text { Règles relatives } \\
\text { aux appels } \\
\text { d'offres }\end{array}$ & Délais & $\begin{array}{c}\text { Autres règles } \\
\text { (Critères de sélection, } \\
\text { critères d'attribution, } \\
\text { cahier des charges et } \\
\text { recours) }\end{array}$ \\
\hline & $\begin{array}{l}\text { d'une valeur supérieure } \\
\text { comme inférieure aux } \\
\text { seuils européens. Les } \\
\text { principes du Traité de } \\
\text { l'UE doivent être } \\
\text { respectés. }\end{array}$ & $\begin{array}{l}\text { autorisant la } \\
\text { procédure simplifiée, } \\
\text { les procédures } \\
\text { européennes } \\
\text { s'appliquent, sauf en } \\
\text { ce qui concerne les } \\
\text { délais et la } \\
\text { publication au } \\
\text { Journal officiel. }\end{array}$ & $\begin{array}{l}\text { Les mêmes règles } \\
\text { s'appliquent aux } \\
\text { secteurs spéciaux. }\end{array}$ & utilisés. & $\begin{array}{l}\text { délai retenu dans la } \\
\text { procédure ouverte } \\
\text { est de } \mathbf{2 0} \text { jours (15 } \\
\text { jours sous forme } \\
\text { électronique). Dans } \\
\text { le cadre de la } \\
\text { procédure } \\
\text { restreinte, le délai } \\
\text { de présentation des } \\
\text { demandes de } \\
\text { participation est de } \\
\mathbf{1 0} \text { jours et de } \mathbf{1 5} \\
\text { jours pour la } \\
\text { soumission des } \\
\text { offres, et il peut être } \\
\text { réduit en cas de } \\
\text { soumission } \\
\text { électronique. } \\
\text { Dialogue compétitif } \\
\mathbf{2 0} \text { jours et } \\
\text { procédure négociée } \\
\mathbf{1 0} \text { jours. }\end{array}$ & seuils. \\
\hline
\end{tabular}




\begin{tabular}{|c|c|c|c|c|c|c|}
\hline État membre & $\begin{array}{l}\text { Instrument } \\
\text { réglementaire }\end{array}$ & Seuils & Méthodes & $\begin{array}{l}\text { Règles relatives aux } \\
\text { appels d'offres }\end{array}$ & Délais & $\begin{array}{c}\text { Autres règles } \\
\text { (Critères de sélection, } \\
\text { critères d'attribution, } \\
\text { cahier des charges et } \\
\text { recours) }\end{array}$ \\
\hline Slovaquie & $\begin{array}{l}\text { La Loi 25/2006 } \\
\text { sur les marchés } \\
\text { publics amendée } \\
\text { par 232/2008 et } \\
442 / 2008 \text { régit les } \\
\text { marchés d'une } \\
\text { valeur inférieure } \\
\text { aux seuils } \\
\text { européens dans le } \\
\text { secteur classique. } \\
\text { Les services } \\
\text { spéciaux ne sont } \\
\text { pas réglementés. } \\
\text { Les services II B } \\
\text { sont régis par les } \\
\text { dispositions } \\
\text { applicables aux } \\
\text { marchés inférieurs } \\
\text { aux seuils } \\
\text { européens. }\end{array}$ & $\begin{array}{l}65000 \text { EUR pour } \\
\text { les biens et les } \\
\text { services et } 360 \\
000 \text { EUR pour les } \\
\text { marchés de } \\
\text { travaux. } \\
30000 \text { EUR pour } \\
\text { les biens et les } \\
\text { services et } 120 \\
000 \text { EUR pour les } \\
\text { marchés de } \\
\text { travaux. } \\
\text { En dessous de ces } \\
\text { derniers seuils, } \\
\text { marchés de faible } \\
\text { valeur. }\end{array}$ & $\begin{array}{l}\text { Au-dessus de la } \\
\text { première } \\
\text { fourchette, } \\
\text { application des } \\
\text { procédures } \\
\text { européennes dans } \\
\text { des délais réduits. } \\
\text { Entre les } \\
\text { fourchettes } \\
\text { supérieures et } \\
\text { inférieures, } \\
\text { application de } \\
\text { procédures } \\
\text { simplifiées. } \\
\text { L'achat direct est } \\
\text { autorisé en dessous } \\
\text { de la fourchette } \\
\text { inférieure. }\end{array}$ & $\begin{array}{l}\text { Au-dessus de la } \\
\text { première fourchette, } \\
\text { publication des avis } \\
\text { de marchés et des } \\
\text { avis d'attribution } \\
\text { identique à celle des } \\
\text { marchés supérieurs } \\
\text { aux seuils } \\
\text { européens, à paraître } \\
\text { dans le journal } \\
\text { électronique des } \\
\text { marchés publics géré } \\
\text { par le responsable } \\
\text { des appels d'offres } \\
\text { (obligatoire). La } \\
\text { publication sur } \\
\text { d'autres supports est } \\
\text { encouragée. } \\
\text { Le journal } \\
\text { électronique, de } \\
\text { même que les autres } \\
\text { supports, peuvent } \\
\text { être utilisés dans le } \\
\text { cadre de la }\end{array}$ & $\begin{array}{l}\text { Première } \\
\text { fourchette : le } \\
\text { délai de } \\
\text { soumission des } \\
\text { offres est de } \mathbf{3 6} \\
\text { jours dans le } \\
\text { cadre de la } \\
\text { procédure ouverte } \\
\text { et de } \mathbf{2 2} \text { jours } \\
\text { dans le cadre de } \\
\text { procédures } \\
\text { restreintes et } \\
\text { négociées. } \\
\text { Entre les } \\
\text { fourchettes } \\
\text { supérieures et } \\
\text { inférieures, les } \\
\text { pouvoirs } \\
\text { adjudicateurs } \\
\text { peuvent } \\
\text { déterminer des } \\
\text { délais } \\
\text { raisonnables. }\end{array}$ & $\begin{array}{l}\text { Les règles } \\
\text { applicables sont } \\
\text { fondamentalement } \\
\text { identiques, que les } \\
\text { marchés soient } \\
\text { inférieurs ou } \\
\text { supérieurs aux seuils } \\
\text { européens. } \\
\text { Cependant, il ne peut } \\
\text { être fait appel des } \\
\text { décisions } \\
\text { d'attribution des } \\
\text { marchés inférieurs } \\
\text { aux deuxièmes } \\
\text { fourchettes. }\end{array}$ \\
\hline
\end{tabular}




\begin{tabular}{|l|l|l|l|l|l|c|}
\hline État membre & $\begin{array}{c}\text { Instrument } \\
\text { réglementaire }\end{array}$ & Seuils & Méthodes & $\begin{array}{l}\text { Règles relatives aux } \\
\text { appels d'offres }\end{array}$ & $\begin{array}{c}\text { Autres règles } \\
\text { (Critères de sélection, } \\
\text { critères d'attribution, } \\
\text { cahier des charges et } \\
\text { recours) }\end{array}$ \\
\hline & & & & $\begin{array}{l}\text { procédure } \\
\text { simplifiée. }\end{array}$ & \\
\hline
\end{tabular}

\begin{tabular}{|c|c|c|c|c|c|c|}
\hline État membre & $\begin{array}{l}\text { Instrument } \\
\text { réglementaire }\end{array}$ & Seuils & Méthodes & $\begin{array}{l}\text { Règles relatives } \\
\text { aux appels } \\
\text { d'offres }\end{array}$ & Délais & $\begin{array}{c}\text { Autres règles } \\
\text { (Critères de sélection, } \\
\text { critères d'attribution, } \\
\text { cahier des charges et } \\
\text { recours) }\end{array}$ \\
\hline Slovénie & $\begin{array}{l}\text { Loi sur la passation } \\
\text { des marchés publics } \\
\text { (ZJN-2) dans le } \\
\text { secteur classique, et } \\
\text { Loi sur la passation } \\
\text { des marchés publics } \\
\text { (ZJNVETPS) dans } \\
\text { les secteurs } \\
\text { spéciaux. } \\
\text { Application des } \\
\text { dispositions du } \\
\text { Traité de l'UE. Les } \\
\text { deux lois régissent } \\
\text { les marchés d'une } \\
\text { valeur inférieure aux }\end{array}$ & $\begin{array}{l}40000 \text { EUR pour } \\
\text { les biens et les } \\
\text { services et } 80000 \\
\text { EUR pour les } \\
\text { travaux. } \\
10000 \text { EUR pour } \\
\text { les biens et les } \\
\text { services et } 20000 \\
\text { EUR pour les } \\
\text { travaux. } \\
\text { En dessous de } \\
\text { cette fourchette } \\
\text { inférieure, } \\
\text { l'attribution de }\end{array}$ & $\begin{array}{l}\text { Les procédures } \\
\text { européennes } \\
\text { peuvent s'appliquer } \\
\text { en dessous du seuil } \\
\text { fixé par l'UE ou les } \\
\text { procédures } \\
\text { simplifiées (à une } \\
\text { ou deux étapes) } \\
\text { avec publication } \\
\text { préalable. } \\
\text { Dans la deuxième } \\
\text { fourchette de } \\
\text { seuils, la procédure } \\
\text { simplifiée avec }\end{array}$ & $\begin{array}{l}\text { Publication sur le } \\
\text { portail Web pour } \\
\text { tous les marchés } \\
\text { dont la } \\
\text { publication est } \\
\text { obligatoire. Au- } \\
\text { dessus de la } \\
\text { première } \\
\text { fourchette, les } \\
\text { avis de marchés, } \\
\text { comme les avis } \\
\text { d'attribution, } \\
\text { doivent être } \\
\text { conformes aux } \\
\text { conditions }\end{array}$ & $\begin{array}{l}\text { Si les procédures } \\
\text { européennes sont } \\
\text { utilisées pour les } \\
\text { marchés inférieurs } \\
\text { aux seuils } \\
\text { européens, les } \\
\text { délais doivent être } \\
\text { fondamentalement } \\
\text { identiques. } \\
\text { Dans les autres } \\
\text { cas, les pouvoirs } \\
\text { adjudicateurs ont } \\
\text { le droit de } \\
\text { déterminer les }\end{array}$ & $\begin{array}{l}\text { Les règles } \\
\text { applicables sont } \\
\text { fondamentalement } \\
\text { identiques, que les } \\
\text { marchés soient } \\
\text { inférieurs ou } \\
\text { supérieurs aux seuils } \\
\text { européens. }\end{array}$ \\
\hline
\end{tabular}




\begin{tabular}{|c|c|c|c|c|c|c|}
\hline État membre & $\begin{array}{l}\text { Instrument } \\
\text { réglementaire }\end{array}$ & Seuils & Méthodes & $\begin{array}{l}\text { Règles relatives } \\
\text { aux appels } \\
\text { d'offres }\end{array}$ & Délais & $\begin{array}{c}\text { Autres règles } \\
\text { (Critères de sélection, } \\
\text { critères d'attribution, } \\
\text { cahier des charges et } \\
\text { recours) }\end{array}$ \\
\hline & $\begin{array}{l}\text { seuils fixés par l'UE. } \\
\text { L'attribution des } \\
\text { marchés de services } \\
\text { II B est encadrée par } \\
\text { la loi sur la passation } \\
\text { des marchés publics } \\
\text { et devrait être } \\
\text { assortie de la } \\
\text { publication d'un avis } \\
\text { de marché. }\end{array}$ & $\begin{array}{l}\text { marchés de faible } \\
\text { valeur s'applique. }\end{array}$ & $\begin{array}{l}\text { appel d'offres } \\
\text { direct est possible } \\
\text { (avec } 3 \text { offres au } \\
\text { minimum). } \\
\text { En dessous de la } \\
\text { fourchette } \\
\text { inférieure, l'achat } \\
\text { direct est autorisé. } \\
\text { Ces seuils et ces } \\
\text { méthodes } \\
\text { s'appliquent } \\
\text { également aux } \\
\text { secteurs spéciaux. }\end{array}$ & $\begin{array}{l}\text { européennes, } \\
\text { dans une forme } \\
\text { toutefois } \\
\text { simplifiée. }\end{array}$ & $\begin{array}{l}\text { délais de } \\
\text { présentation des } \\
\text { demandes de } \\
\text { participation et de } \\
\text { soumission des } \\
\text { offres, selon la } \\
\text { complexité et la } \\
\text { nature des } \\
\text { marchés. }\end{array}$ & \\
\hline
\end{tabular}

\begin{tabular}{|l|l|l|l|l|l|l|}
\hline État membre & \multicolumn{1}{|l|}{$\begin{array}{l}\text { Instrument } \\
\text { réglementaire }\end{array}$} & Seuils & Méthodes & $\begin{array}{l}\text { Règles relatives } \\
\text { aux appels } \\
\text { d'offres }\end{array}$ & $\begin{array}{c}\text { Autres règles } \\
\text { Délais }\end{array}$ & $\begin{array}{c}\text { Critères de sélection, } \\
\text { critères d'attribution, } \\
\text { cahier des charges et } \\
\text { recours) }\end{array}$ \\
\hline Espagne & $\begin{array}{l}\text { Loi 30/2007 } \\
\text { (marchés du secteur } \\
\text { public) }\end{array}$ & & & $\begin{array}{l}\text { Avis normalisés } \\
\text { spécifiques pour } \\
\text { les marchés }\end{array}$ & $\begin{array}{l}\text { S'agissant des } \\
\text { marchés } \\
\text { inférieurs aux }\end{array}$ & $\begin{array}{l}\text { Les règles } \\
\text { applicables sont } \\
\text { fondamentalement }\end{array}$ \\
\hline
\end{tabular}




\begin{tabular}{|c|c|c|c|c|c|c|}
\hline État membre & $\begin{array}{c}\text { Instrument } \\
\text { réglementaire }\end{array}$ & Seuils & Méthodes & $\begin{array}{c}\text { Règles relatives } \\
\text { aux appels } \\
\text { d'offres }\end{array}$ & Délais & $\begin{array}{c}\text { Autres règles } \\
\text { (Critères de sélection, } \\
\text { critères d'attribution, } \\
\text { cahier des charges et } \\
\text { recours) }\end{array}$ \\
\hline & $\begin{array}{l}\text { Loi } 31 / 2007 \\
\text { (secteurs spéciaux). } \\
\text { Décret royal } \\
1098 / 2001 . \\
\text { Décret royal } \\
817 / 2009 .\end{array}$ & & & $\begin{array}{l}\text { inférieurs aux } \\
\text { seuils européens. } \\
\text { Aucune } \\
\text { réglementation } \\
\text { pour les marchés } \\
\text { passés dans les } \\
\text { secteurs spéciaux } \\
\text { dont la valeur est } \\
\text { inférieure aux } \\
\text { seuils de la } \\
\text { Directive } \\
\text { 2004/18. }\end{array}$ & $\begin{array}{l}\text { seuils européens } \\
\text { dans le secteur } \\
\text { public, délai de } \\
\text { soumission des } \\
\text { offres d'au moins } \\
\mathbf{1 5} \text { jours } \\
\text { (procédure } \\
\text { ouverte ou } \\
\text { restreinte). }\end{array}$ & $\begin{array}{l}\text { identiques, que les } \\
\text { marchés soient } \\
\text { inférieurs ou } \\
\text { supérieurs aux seuils } \\
\text { européens. }\end{array}$ \\
\hline Suède & $\begin{array}{l}\text { Loi sur les marchés } \\
\text { publics (LOU) dans } \\
\text { le secteur classique } \\
\text { et loi sur les marchés } \\
\text { publics (LUF) dans } \\
\text { les secteurs } \\
\text { spéciaux. } \\
\text { Ces lois couvrent les } \\
\text { marchés dont la } \\
\text { valeur est inférieure } \\
\text { aux seuils fixés par } \\
\text { l'UE. }\end{array}$ & $\begin{array}{l}\text { Aucun seuil } \\
\text { national. } \\
\text { L'achat direct est } \\
\text { autorisé pour les } \\
\text { marchés de faible } \\
\text { valeur sur libre } \\
\text { choix du pouvoir } \\
\text { adjudicateur } \\
\text { (même situation } \\
\text { dans le secteur } \\
\text { classique et dans } \\
\text { les secteurs }\end{array}$ & $\begin{array}{l}\text { Application soit } \\
\text { d'une procédure } \\
\text { simplifiée ouverte, } \\
\text { soit d'une } \\
\text { procédure } \\
\text { restreinte avec } \\
\text { publication } \\
\text { préalable. }\end{array}$ & $\begin{array}{l}\text { Publication } \\
\text { obligatoire des } \\
\text { avis de marchés } \\
\text { dans des bases de } \\
\text { données } \\
\text { généralement } \\
\text { acceptées } \\
\text { (opérateurs privés } \\
\text { dûment agréés). }\end{array}$ & $\begin{array}{l}\text { Le délai de } \\
\text { présentation des } \\
\text { demandes de } \\
\text { participation doit } \\
\text { être d'au } \\
\text { minimum } \mathbf{1 0} \\
\text { jours ; pour la } \\
\text { soumission des } \\
\text { offres, un délai } \\
\text { raisonnable est } \\
\text { fixé par le } \\
\text { pouvoir }\end{array}$ & $\begin{array}{l}\text { Fondamentalement, } \\
\text { les mêmes règles, } \\
\text { quoique simplifiées, } \\
\text { s'appliquent en } \\
\text { dessous comme au- } \\
\text { dessus des seuils } \\
\text { fixés par l'UE. }\end{array}$ \\
\hline
\end{tabular}




\begin{tabular}{|l|l|l|l|l|l|l|}
\hline État membre & \multicolumn{1}{|c|}{$\begin{array}{l}\text { Instrument } \\
\text { réglementaire }\end{array}$} & Seuils & Méthodes & $\begin{array}{c}\text { Règles relatives } \\
\text { aux appels } \\
\text { d'offres }\end{array}$ & $\begin{array}{c}\text { Autres règles } \\
\text { (Critères de sélection, } \\
\text { critères d'attribution, } \\
\text { cahier des charges et } \\
\text { recours }\end{array}$ \\
\hline & $\begin{array}{l}\text { Les obligations } \\
\text { visées dans le Traité } \\
\text { de l'UE sont } \\
\text { respectées. } \\
\text { Les services II B } \\
\text { sont couverts par le } \\
\text { régime simplifié de } \\
\text { la LOU et de la } \\
\text { LUF. }\end{array}$ & spéciaux). & & & adjudicateur. \\
\hline
\end{tabular}

\begin{tabular}{|l|l|l|l|l|l|l|}
\hline État membre & \multicolumn{1}{|c|}{$\begin{array}{c}\text { Instrument } \\
\text { réglementaire }\end{array}$} & Seuils & Méthodes & $\begin{array}{c}\text { Règles relatives } \\
\text { aux appels } \\
\text { d'offres }\end{array}$ & $\begin{array}{c}\text { Autres règles } \\
\text { Délais } \\
\text { (Critères de sélection, } \\
\text { critères d'attribution, } \\
\text { cahier des charges et } \\
\text { recours) }\end{array}$ \\
\hline $\begin{array}{l}\text { Royaume- } \\
\text { Uni }\end{array}$ & $\begin{array}{l}\text { Les réglementations } \\
\text { S1 2006/5 relatives } \\
\text { aux marchés publics } \\
\text { et les } \\
\text { réglementations S1 } \\
\text { 2006/6 régissant la } \\
\text { passation des } \\
\text { marchés publics }\end{array}$ & Non précisé & $\begin{array}{l}\text { À titre indicatif, les } \\
\text { exigences en } \\
\text { matière } \\
\text { «d'optimisation } \\
\text { des ressources } \\
\text { impliquent de } \\
\text { recourir à des } \\
\text { procédures }\end{array}$ & Non précisé & Non précisé & Non précisé \\
\hline
\end{tabular}




\begin{tabular}{|l|l|l|l|l|l|}
\hline État membre & \multicolumn{1}{|c|}{$\begin{array}{l}\text { Instrument } \\
\text { réglementaire }\end{array}$} & Seuils & Méthodes & $\begin{array}{c}\text { Règles relatives } \\
\text { aux appels } \\
\text { d'offres }\end{array}$ & $\begin{array}{c}\text { Autres règles } \\
\text { (Critères de sélection, } \\
\text { critères d'attribution, } \\
\text { cahier des charges et } \\
\text { recours }\end{array}$ \\
\hline & $\begin{array}{l}\text { dans les secteurs } \\
\text { spéciaux transposent } \\
\text { les directives } \\
\text { européennes pour les } \\
\text { marchés supérieurs } \\
\text { aux seuils } \\
\text { européens. Aucun } \\
\text { instrument } \\
\text { réglementaire n'est } \\
\text { prévu pour les } \\
\text { marchés de valeur } \\
\text { inférieure aux seuils } \\
\text { européens. Les } \\
\text { obligations du Traité } \\
\text { de l'UE doivent être } \\
\text { respectées. }\end{array}$ & $\begin{array}{l}\text { concurrentielles } \\
\text { ouvertes. }\end{array}$ & & & \\
\hline
\end{tabular}


ANNEXE 2 : QUESTIONNAIRE

\title{
ENQUÊTE SIGMA : COMMENT LES ÉTATS MEMBRES DE L'UE RÉGLEMENTENT LA PASSATION DES MARCHÉS PUBLICS EN DEHORS DES DIRECTIVES EUROPÉENNES
}

Partie I.

\author{
Règles et autres procédures d'intérêt particulier pour la passation de \\ marchés dont la valeur est inférieure aux seuils fixés par l'UE
}

Question 1. Instrument(s) réglementaire(s) ou orientations sur l'attribution des marchés dont la valeur est inférieure aux seuils de l'UE

- $\quad$ Tout d'abord, par souci de précision, veuillez indiquer quels sont le(s) instrument(s) réglementaire(s) applicable(s) en matière d'attribution des marchés couverts par les Directives européennes 2004/17 et 2004/18 (supérieurs aux seuils européens).

- L'instrument réglementaire stipule-t-il de respecter les obligations du Traité de l'UE dans la passation de marchés inférieurs aux seuils européens?

- Le même instrument réglementaire s'applique-t-il aux marchés dont la valeur est inférieure aux seuils européens ? À défaut, veuillez préciser quels sont le ou les instruments réglementaires applicables en matière d'attribution de marchés dont la valeur est inférieure aux seuils européens (par exemple, loi sur les marchés publics, réglementation distincte ou autres actes administratifs).

- Les marchés dont la valeur est inférieure aux seuils européens font-ils l'objet d'instruments réglementaires identiques pour le secteur classique et pour les secteurs spéciaux?

- $\quad$ Existe-t-il un instrument réglementaire dédié aux marchés de services II B dont la valeur est inférieure aux seuils européens ? Veuillez spécifier et décrire les principales caractéristiques des procédures d'adjudication pour cette catégorie de services.

- $\quad$ Si l'attribution des contrats inférieurs aux seuils est principalement ou exclusivement régie par des orientations (par exemple, au Royaume-Uni) plutôt que par des instruments réglementaires, veuillez indiquer comment accéder à ces orientations (auquel cas, veuillez inscrire, le cas échéant, non précisé (N/A) pour les questions suivantes liées aux instruments réglementaires).

\section{Question 2. Seuils nationaux applicables, hors seuils fixés par l'UE}

Outre les seuils au-delà desquels les règles européennes s'appliquent, avez-vous recours à des seuils nationaux ? Veuillez spécifier le rôle de ces seuils (par exemple, utilisation de procédures simplifiées, achat direct, demandes de devis). Ces seuils nationaux sont-ils les mêmes dans le secteur classique et dans les secteurs spéciaux? 


\section{Question 3. Procédures de passation de marchés d'une valeur inférieure aux seuils européens}

- Veuillez indiquer les procédures de passation de marchés (par exemple, appel d'offres ouvert ou restreint, demande de devis, achat direct et autres procédures simplifiées) autorisées en dessous des seuils fixés par l'UE, ainsi que les conditions ou les seuils qui déclenchent leur application ?

- $\quad$ Ces procédures sont-elles les mêmes dans le secteur public et dans les secteurs spéciaux ?

\section{Question 4. Règles applicables en matière d'appels d'offres inférieurs aux seuils européens}

Quelles sont les règles applicables pour les appels d'offres inférieurs aux seuils européens en termes de conditions de publication, ou quelles sont les possibilités d'émettre des appels d'offres directs sans publication préalable?

- $\quad$ En cas de publication, quels supports doivent être utilisés ?

- $\quad$ Pour ce qui précède, existe-t-il des différences entre le secteur public et les secteurs spéciaux ?

\section{Question 5. Règles de publication}

En cas d'offres ouvertes, quels types d'avis sont imposés (par exemple, avis d'information préalable, avis de marché et avis d'attribution) ? Les modèles normalisés utilisés pour les avis diffèrent-ils de ceux proposés par les directives européennes?

- $\quad$ Ces procédures sont-elles les mêmes dans le secteur public et dans les secteurs spéciaux ?

Question 6. Délais de présentation des demandes de participation et de soumission des offres

Veuillez spécifier les délais de présentation des demandes de participation et de soumission des offres observés dans le cadre des procédures de passation de marchés énumérées à la question 3 (procédures de passation de marchés) ci-dessus.

Demandes de participation $=$

Offres $=$

\section{Question 7. Moyens de présentation des demandes de participation et de soumission des} offres

Existe-t-il des règles relatives à la présentation des demandes de participation et de soumission des offres (par exemple, par courrier ou électroniquement) ? Si oui, veuillez préciser.

\section{Question 8. $\quad$ Politiques et règles applicables en matière de sélection qualitative}

Existe-t-il des politiques, des règles ou des procédures pour déterminer les qualifications requises de la part d'un soumissionnaire pour exécuter un marché ? Veuillez préciser si elles diffèrent des règles applicables au-dessus des seuils européens. 
Question 9. Politiques et règles applicables en matière d'examen des offres et de critères d'attribution

- Existe-t-il des politiques, des règles ou des procédures pour l'examen des offres et l'application de critères d'attribution? Veuillez préciser si elles diffèrent des règles applicables au-dessus des seuils européens.

- $\quad$ Existe-t-il des règles pour déterminer les offres anormalement basses ?

\section{Question 10. Règles relatives au cahier des charges}

Existe-t-il des règles pour définir le cahier des charges ? Veuillez préciser si elles diffèrent des règles applicables au-dessus des seuils européens.

Question 11. Politiques et règles applicables en matière de passation des marchés publics en ligne

Existe-t-il des politiques ou des règles pour la passation des marchés en ligne ? Veuillez préciser si elles diffèrent des règles applicables au-dessus des seuils européens.

\section{Question 12. Politiques et règles applicables en matière d'accords-cadres}

- $\quad$ Existe-t-il des politiques ou des règles pour l'attribution d'accords-cadres ? Veuillez préciser si elles diffèrent des règles applicables au-dessus des seuils européens.

\section{Question 13. Procédures en vigueur en matière de plaintes, de révision et de recours}

Quelles sont les procédures en vigueur en matière de plaintes, de révision et de recours ? Veuillez préciser si elles diffèrent des règles applicables au-dessus des seuils européens. Veuillez spécifier les instances habilitées à examiner les appels. Ces mêmes instances traitent-elles également des procédures applicables au-dessus des seuils européens? 
Partie II. Règles et procédures communes non couvertes en détail dans les Directives européennes (mais fréquemment incluses dans les régimes de passation des marchés des États membres de l'UE)

\section{Question 14. Organisation des procédures d'appel d'offres}

- $\quad$ Les pouvoirs adjudicateurs sont-ils tenus d'instaurer des commissions d'appels d'offres permanentes ou ad-hoc pour gérer le processus d'appel d'offres ? Si oui, quels sont les principales fonctions et le mandat de ces commissions ? La composition et la responsabilité de ces commissions sont-elles réglementées par la loi ou par le droit dérivé ?

- Quelle personne/instance est autorisée à attribuer un marché pour le compte du pouvoir adjudicateur ? Cette procédure est-elle réglementée par la loi ou par le droit dérivé ?

\section{Question 15. Qualification et dossier d'appels d'offres}

- $\quad$ L'instrument réglementaire applicable prescrit-il le contenu détaillé de toute documentation distincte de présélection/sélection? Si oui, veuillez spécifier les principales règles applicables.

- $\quad$ L'instrument réglementaire prescrit-il l'utilisation d'un dossier d'appel d'offres standard ou d'un modèle de documentation pour la fourniture de biens, de travaux et de services ? Si oui, veuillez spécifier les principales règles ou renvoyer au chapitre concerné par l'instrument réglementaire applicable.

- $\quad$ À l'issue d'un appel d'offres, le soumissionnaire doit-il payer des frais pour se voir remettre le dossier d'appel d'offres? Si oui, veuillez spécifier la règle applicable.

\section{Question 16. Ouverture des plis}

- Quelles sont les règles applicables en matière d'ouverture des offres ? Les offres doivent-elles être ouvertes en séance publique ? Si oui, qui peut assister à l'ouverture, ou l'ouverture doit-elle avoir lieu à huis clos?

- $\quad$ Existe-t-il des différences dans les procédures d'ouverture eu égard à la démarche suivie, la taille ou la nature du marché (biens/services/travaux)?

\section{Question 17. Garanties d'adjudication et d'exécution}

L'instrument réglementaire autorise-t-il les pouvoirs/entités adjudicatrices à exiger d'assortir la soumission d'une offre d'une garantie d'adjudication ? Si oui, quelles sont les règles et le montant d'une telle garantie?

- $\quad$ L'instrument réglementaire autorise-t-il les pouvoirs/entités adjudicatrices à assortir la conclusion d'un marché avec un soumissionnaire d'une garantie d'exécution ? Si oui, quelles sont les règles et le montant d'une telle garantie?

\section{Question 18. Annulation des procédures d'appel d'offres}

L'instrument réglementaire couvre-t-il l'annulation des procédures d'appel d'offres ? Si oui, veuillez en préciser les règles ? 


\section{Question 19. Délai de validité des offres}

L'instrument réglementaire soumet-il les offres à un délai de validité, y compris à d'éventuels prolongements de ce délai de validité ? Si oui, veuillez en préciser les règles.

\section{Question 20. Utilisation du système de la double enveloppe}

L'instrument réglementaire prescrit-il l'utilisation du système de la double enveloppe (offres techniques et financières soumises dans deux plis distincts) ? Si oui, veuillez en préciser les règles.

\section{Question 21. Conflit d'intérêt}

- $\quad$ Le régime réglementaire prévoit-il l'application de règles aux marchés publics sur la question du conflit d'intérêt? Si oui, veuillez en préciser les règles.

Question 22. Règles particulières applicables à l'attribution de marchés de services de conseil ou d'autres services intellectuels

L'instrument réglementaire définit-il des règles et des procédures particulières pour l'attribution de services de conseil/services intellectuels? Si oui, veuillez en préciser les règles.

Question 23. Changements ou initiatives planifiés dans la réglementation des marchés publics non couverts par les directives européennes (partie I et II du questionnaire)

En dehors de l'harmonisation requise avec le droit européen et des initiatives nationales portant sur la loi des concessions/passation des marchés publics, envisagez-vous d'amender le cadre réglementaire, hors champ couvert par les directives européennes? Si oui, veuillez préciser. 